\title{
Simulating the Transition from Drizzling Marine Stratocumulus to Boundary Layer Cumulus with a Mesoscale Model
}

\author{
David B. Mechem and Yefim L. Kogan \\ Cooperative Institute for Mesoscale Meteorological Studies, University of Oklahoma, Norman, Oklahoma
}

(Manuscript received 14 October 2002, in final form 24 March 2003)

\begin{abstract}
A case of coastal California summer season boundary layer cloud has been simulated with the U.S. Navy Coupled Ocean-Atmosphere Mesoscale Prediction System and the results analyzed in the context of consistency with conclusions derived from large eddy simulation-based (LES) studies. Results show a pronounced diurnal cycle and fair agreement with satellite-derived observations of liquid water path. When drizzle processes are included, a significant degree of mesoscale organization emerges in the form of cloud bands, accompanied by a transition from a well-mixed boundary layer topped by unbroken stratocumulus cloud into a more potentially unstable, convective boundary layer regime. The transition and the subsequent development of mesoscale variability is analogous to the drizzle-induced cloud breakup produced in large eddy simulation studies. The dynamics of the pure stratocumulus cloud are dictated by the model's subgrid parameterization, while the more convective regime exhibits appreciable vertical velocities characteristic of an ensemble of cumulus updrafts. The existence of convective updrafts is tied to a weak drizzle-induced decoupling of the cloud and subcloud layer, after which air of higher equivalent potential temperature $\left(\theta_{e}\right)$ can pool at the surface. Some similarities to the propagation of deep convection are also noted.
\end{abstract}

\section{Introduction}

Subtropical marine stratocumulus clouds are important on multiple scales. These large cloud systems have a pronounced effect on the global radiation budget and are possibly an important feedback process in the issue of global climate change. Slingo (1990) reported that for some global climate models, a $20 \%$ increase in the area of the globe covered by low-level stratus would offset the predicted temperature increase from a doubling of carbon dioxide $\left(\mathrm{CO}_{2}\right)$ concentration. On shorter timescales, these quiescent clouds may be associated with fog or drizzle and can have a pronounced influence on aerial and marine operations.

Numerical experiments using large eddy simulation (LES) models, run at high spatial resolution, have supplied insight into cloud-topped boundary layers (CTBLs; e.g., Moeng 1986; Kogan et al. 1995; Moeng et al. 1996; Stevens et al. 1998; Khairoutdinov and Kogan 1999). The bulk cloud properties (cloud base, height, fraction, and geometry) appear to result from a subtle balance between surface fluxes of heat and moisture, cloud-top longwave radiative flux (plus shortwave

Corresponding author address: David B. Mechem, CIMMS, University of Oklahoma, 100 E. Boyd, Room 1110, Norman, OK 730191011.

E-mail: dmechem@ou.edu radiative flux during the day), large-scale subsidence divergence, and if present, drizzle flux.

Regional simulations of marine CTBLs are rarer. Wang et al. (1993) generalized the two-layer, one-dimensional model of Wang (1993) to form what is essentially a regional mixed layer model. The model was forced with mean large-scale conditions of the eastern subtropical Pacific and produces a pattern of cloudiness qualitatively similar to the observed satellite imagery. The model demonstrates the importance of horizontal advection on cloud-top height and moisture budgets, and shows sensitivities to large-scale subsidence divergence, shortwave radiation, and drizzle, all of which tend to significantly decrease cloud fraction. Mocko and Cotton (1995) used a mesoscale model to test fractional cloudiness parameterizations in situations of marine stratocumulus. Their model was run in a nested grid configuration, with the finest mesh having a 5-km grid spacing and covering a region that marked the transition from cumulus to solid stratocumulus. McCaa and Bretherton (2003b, manuscript submitted to Mon. Wea. Rev.) showed that a mesoscale model, equipped with parameterizations for CTBL turbulence and shallow cumulus, is able to produce realistic seasonal mean stratocumulus cloud structure, including the transition from stratocumulus to trade cumulus.

As computer power increases, it becomes possible to run operationally regional mesoscale models with hor- 
izontal grid spacings similar to an LES domain size (2$3 \mathrm{~km}$ ), and it becomes important to address whether mesoscale models are correctly representing the dynamics of the CTBL. Using a very fine grid spacing $[O(100$ $\mathrm{m})$, an LES model explicitly represents the turbulent eddies that contain most of the kinetic energy, leaving the subgrid-scale (SGS) eddies to lie (hopefully) within the inertial subrange, where they passively transfer energy to successively smaller scales. In addition to this energy cascade, SGS effects are important at internal flow boundaries such as the surface or an entrainment interface. Assuming the SGS eddies are within the inertial subrange, the model solution should not be especially sensitive to the actual SGS parameterization used (Moeng et al. 1996). Unfortunately, this assumption is no longer valid when the resolution is degraded to "mesoscale" grid spacing $(2-18 \mathrm{~km}$, the bounds of the horizontal grid interval used in this study).

At these mesoscale grid spacings, it is desirable to capture two characteristics of a midlatitude cloud system. First, the model needs to be able to produce a reasonable representation of unbroken stratocumulus. Accurate portrayal of cloud microphysical processes is crucial, and liquid water content and cloud thickness should be within bounds established by observations and climatology. Stratocumulus at this stage are characterized largely by radiative cooling, which drives eddies spanning the depth of the well-mixed boundary layer. These eddies are present in LES simulations but are too small to be resolved by mesoscale grids and present a challenging test to a model's subgrid parameterization scheme.

The second effect to be produced is the transition from unbroken boundary layer stratocumulus to the broken, boundary layer cumulus regime. Using a two-dimensional cloud model, Krueger et al. (1995) showed that steadily increasing the sea surface temperature (SST) leads to a stratocumulus-to-cumulus transition over a multiday period. Wyant et al. (1997) formulated a conceptual model to describe how this cloud breakup phenomenon can occur. Over a period of days, when unbroken cloud moves over warmer water and the increased surface latent heat flux leads to stronger cloudtop entrainment, a weakly stable layer below cloud base is produced, leading to a decoupling of the cloud layer from the subcloud layer. The stratification allows only the strongest eddies, manifest as cumuli, to span the entire planetary boundary layer (PBL) depth. Although they detrain liquid water into the cloud deck, the vigorous cumulus updrafts also serve to increase the entrainment of dry air above the inversion, resulting in a net thinning of the stratocumulus. Building on prior work by Turton and Nicholls (1987) and Bretherton and Wyant (1997), Stevens (2000) argues that a threshold of buoyancy flux ratio (quotient of integrated negative buoyancy flux to integrated positive buoyancy flux) may be a reasonable proxy for distinguishing well-mixed PBL circulations from decoupled, more convective re- gimes, and hence may be a useful predictor of the transition. LES results by Lewellen and Lewellen (2002) represent the transition as an evolution in cloud fraction accompanying the shift between boundary circulation regimes, defined by whether the eddies span the full PBL or solely the cloud or subcloud layers.

Observational and modeling studies suggest that drizzle can lead to a transition and enhance the breakup of a cloud field. In their conceptual model of boundary layer cloud evolution, Paluch and Lenschow (1991) suggest that evaporating drizzle will stabilize the PBL with respect to surface-based dry-adiabatic ascent. Cumuli associated with the resulting potential instability are likely to be the result, along with subsequent breakup of the cloud deck. Wang and Wang (1994) used a 1-D turbulence closure model to demonstrate that evaporation of drizzle in the subcloud layer tends to decouple the cloud and subcloud layers. Their model creates scattered clouds, which the authors take to be representative of cumulus that couple the cloud and subcloud layers. An LES study (Stevens et al. 1998) demonstrates that rapid cloud breakup can take place as drizzle drops fall through the subcloud layer and evaporate, stabilizing the subcloud layer and reducing the vertical fluxes such that surface fluxes of heat and moisture accumulate in the surface layer. The accumulation leads to potential instability in the stratified boundary layer, which is realized in the form of a field of boundary layer cumulus. The LES results typically show a thinning of the cloud deck under the influence of drizzle, though the Wyant et al. model outlined above has not been applied to address stratocumulus breakup in the context of drizzle. Accounting for drizzle typically produces a net decrease in entrainment, but the Wyant et al. explanation of cloud thinning relies on an increase in the ratio of dry air entrainment to cloud base moisture flux. Even in a decoupled, stably stratified boundary layer, there can be considerable interaction between subcloud and cloud layers through the deep cumulus, whereby the surface layer is ventilated and moisture supplied to the cloud deck. Because of these competing effects, it is unclear under what conditions cloud breakup accompanies a drizzle-induced transition.

In this study, the U.S. Navy Coupled Ocean-Atmosphere Mesoscale Prediction System (COAMPS ${ }^{1}$; Hodur 1997) has been applied to a case of coastal California summertime stratocumulus. We implement a new, twomoment microphysical scheme (Khairoutdinov and Kogan 2000) into COAMPS and show that a regional model can create and maintain reasonable stratocumulus cloud fields. The analysis is concentrated on the fine 2$\mathrm{km}$ mesh and analyzed in the context of consistency with conclusions derived from LES-based studies. COAMPS is run in a nested configuration and on the finest mesh $(2 \mathrm{~km})$ can mimic a diurnal cycle in cloud

\footnotetext{
${ }^{1}$ COAMPS is a trademark of the Naval Research Laboratory.
} 


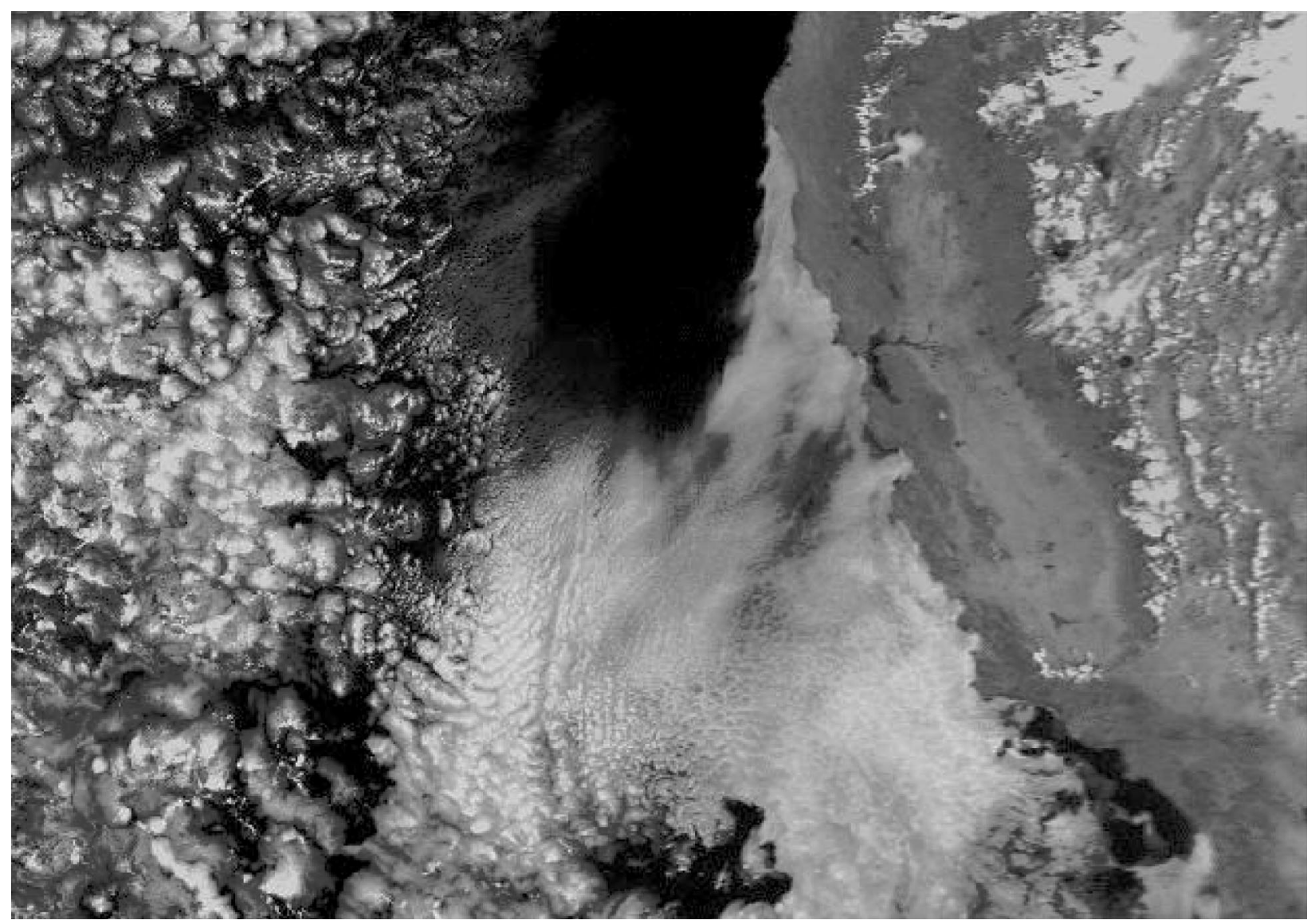

FIG. 1. Multiband AVHRR composite of visible and infrared bands for 1743 UTC 25 Jul 1997.

thickness and produce a cloud pattern organized on the mesoscale and accompanied by a drizzle-induced transition from pure, unbroken stratocumulus to boundary layer cumulus that occurs over the period of a few hours. Many previous studies have attempted to explain the characteristic aspect ratios of organized mesoscale features (open and closed mesoscale convective cells) over the subtropical oceans (see, e.g., Shao and Randall 1996), but we believe that ours is the first study using a regional model to demonstrate mesoscale organization arising from the effects of drizzle. The presence of drizzle seems to be crucial in producing the organized cloud bands on a short timescale and has a complicated nonlinear effect on cloud cover, since it depletes cloud water while also damping boundary layer energetics, reducing drying of the PBL via entrainment. The sensitivity of cloud system properties to depletion of cloud droplets and subsequent enhancement of drizzle production efficiency is explored through a sensitivity experiment where cloud droplet number concentration is held constant.

\section{Case selection and model configuration}

The cloud system over the California coastal region on 25 July 1997 is representative of a typical summer stratocumulus event. Figure 1 shows not only the extent of the cloud system but a wide array of spatial inhomogeneity. Near the coast are unbroken stratus, and away from the coast the clouds appear more convective in nature, though still restricted to the boundary layer. Farther west, the cloud field becomes dominated by closed cellular convective elements. This case has also been investigated by Kong (2002), who explored the formation and dissipation of coastal fog and stratus in the San Francisco Bay area.

Simulations are performed using COAMPS, a threedimensional regional model developed by the Naval Research Laboratory (Hodur 1997). COAMPS dynamics are nonhydrostatic and compressible, using the timesplitting method to integrate the acoustically active terms. A 1.5-order turbulence closure scheme parameterizes subgrid-scale motions ["Level 2.5" in Mellor and Yamada (1982)] and includes a prognostic equation for turbulent kinetic energy with a mixing length dependent upon the atmospheric stratification. Longwave and shortwave radiative effects are included.

The limitations of the commonly employed Kessler (1969) microphysical parameterization are well known (see Chen and Cotton 1987; Baker 1993) and arise from the sensitivity to the parameters defining the scheme. 
The autoconversion threshold in the original formulation is $1 \mathrm{~g} \mathrm{~kg}^{-1}$, a value designed for strong convective clouds but far too large for marine stratocumulus, which have typical liquid water contents of $0.2-0.8 \mathrm{~g} \mathrm{~kg}^{-1}$ and rarely exceed $1 \mathrm{~g} \mathrm{~kg}^{-1}$. The Kessler scheme seems ill suited when applied to a boundary layer topped by a stratocumulus cloud deck that might be drizzling. If used for marine stratocumulus, the scheme will 1) produce no drizzle at all if the autoconversion threshold is not reached; 2) produce drizzle that falls out at an unrealistically large rate, since the fall speed relation is tuned for large convective rain drops; or 3) produce drizzle quantities independent of the ambient cloud condensation nuclei $(\mathrm{CCN})$ concentration. The third item is especially crucial, since past work (Twomey 1977; Albrecht 1989; Stevens et al. 1998) shows that CCN load can have a marked effect on boundary layer dynamics through microphysical and radiative processes. A common procedure when using the Kessler scheme for marine stratocumulus is to reduce the autoconversion threshold, effectively putting an upper bound on the cloud liquid water content. A value of $0.5 \mathrm{~g} \mathrm{~kg}^{-1}$ is typical. While this does tend to bring the cloud water content more in line with observed stratocumulus, the latter two issues listed above are still present, so the approach is of little practical value and not advisable.

The scheme of Khairoutdinov and Kogan (2000; scheme hereafter referred to as KK) has been implemented into COAMPS. The KK parameterization is based on the partial moments of the drop size distribution, and like other bulk schemes, it segments liquid water into a precipitating part (drizzle water) and a nonprecipitating part (cloud water). In addition, equations for number concentration of cloud droplet, drizzle drop, and cloud condensation nuclei are solved to total five prognostic variables $\left(q_{c}, q_{r}, N_{c}, N_{r}, N_{\mathrm{CCN}}\right)$. In contrast to the $C S^{k}$ activation used by Khairoutdinov and Kogan in their LES-based test of the bulk scheme, condensation in this study is based on simple saturation adjustment (i.e., supersaturation is not predicted), and CCN activation is parameterized by the empirical formulas of Martin et al. (1994) and O'Dowd et al. (1996) that relate bulk CCN and cloud droplet concentrations. Autoconversion and accretion rates are formulated using multiple regression of explicitly resolved drop size spectra from a large eddy simulation. Although intrinsically a local scheme, KK has been applied to aircraft data and was demonstrated to be a good predictor of drizzle water quantity for a wide range of cloud droplet concentrations (Wood 2000). Including droplet concentration enables the model to respond to the ambient $\mathrm{CCN}$ load and to capture the increase in drizzle production efficiency as cloud droplets become scavenged through autoconversion and accretion processes.

Since the drizzle scheme includes a prognostic equation for CCN concentration, initial and boundary conditions for this quantity are required. Recently, methods have been developed to retrieve $\mathrm{CCN}$ profiles from sat- ellite data, but these methods are currently in their embryonic stages (Mishchenko et al. 1997). For this experiment, $\mathrm{CCN}$ concentration was assumed to have a value of $45 \mathrm{~cm}^{-3}$ and be homogeneous over the entire domain. We take this number to be representative of a very clean marine air mass. Figure 12 of Albrecht et al. (1988) shows a range in PBL CCN concentration from 40 to $100 \mathrm{~cm}^{-3}$ for one of the cases during the First International Satellite Cloud Climatology Project (ISCCP) Regional Experiment field project off the California coast, and Passive Cavity Aerosol Spectrometer Probe (aerosol) values range from 20 to $70 \mathrm{~cm}^{-3}$ for one of the clean airmass cases in Atlantic Stratocumulus Transition Experiment (Fig. 7 in Martin et al. 1994). The value of $45 \mathrm{~cm}^{-3}$ used in the study is on the low side of this range but is reasonable for a noncontinental air mass and consistent with the flow pattern on 25 July. Boundary conditions for $\mathrm{CCN}$ are fixed at the initial value, and in situ sources are neglected.

COAMPS is run in a one-way nested configuration shown in Fig. 2a, with domains of 18, 6, and $2 \mathrm{~km}$ in horizontal grid spacing. The 2-km mesh is located a significant distance from the coast and from the coarse mesh domain boundaries in order to avoid the presence of topographic forcing near the coast and the corruption of the fine mesh solution from the forced boundary conditions applied to the coarse mesh. Figure $2 b$ shows the vertical grid in the lowest $1500 \mathrm{~m}$ of the domain. The grid size ranges from $10 \mathrm{~m}$ near the surface to nearly $800 \mathrm{~m}$ at the model top. For simulations of marine stratocumulus, grid spacing in the boundary layer and near the inversion should be as fine as is practical given computer memory and processing speed constraints. Climatologically, the inversion height is strongly correlated with SST and slopes upward away from shore. Therefore, given a stretched grid, the vertical resolution of the inversion worsens with distance from the coast.

Two 12-h COAMPS simulations are performed to serve as a preforecast in order to obtain a reasonable boundary layer thermodynamic and cloud field structure. The importance of beginning the actual simulation with a preforecast as opposed to beginning from a cold start has been shown by Kong (2002). Runs beginning from a cold start vastly underestimate marine boundary layer humidity and cloud cover. The preforecast is begun at 0000 UTC 24 July 1997 using the Naval Operational Global Atmospheric Prediction System analysis and undergoes two update cycles, one at 1200 UTC and the second after the preforecast has completed at 0000 UTC 25 July 1997. The preforecasts were run using the operational Kessler microphysics scheme in order to ensure that all experiments would begin from the same initial conditions. The simulations themselves are $24 \mathrm{~h}$ in length and begin after the two 12-h update cycles. Throughout the paper comparisons are periodically made between the control run $(\mathrm{KK})$ and a sensitivity experiment ("ND" - no drizzle) that uses the operational Kessler microphysical parameterization. At liquid 
(a)

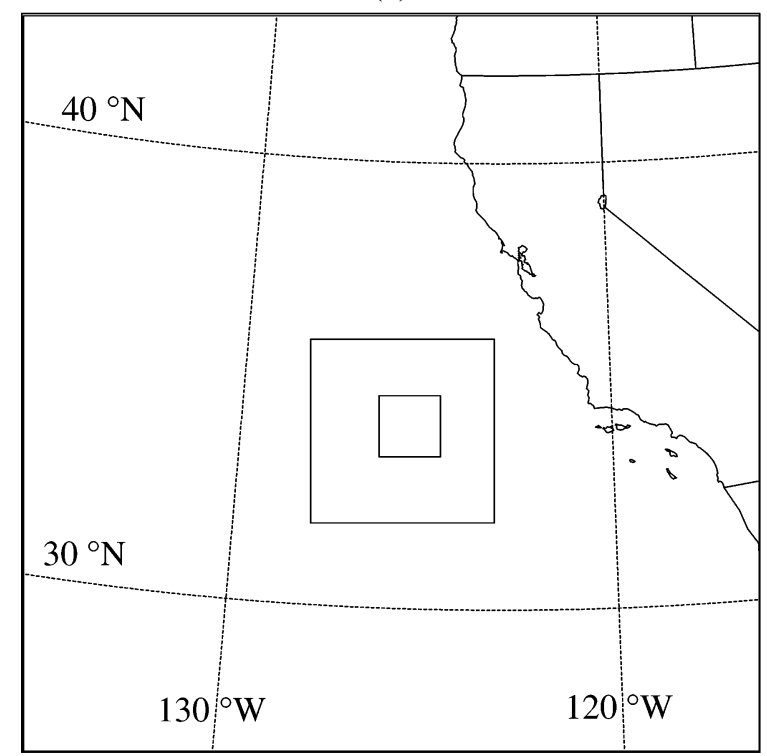

(b)

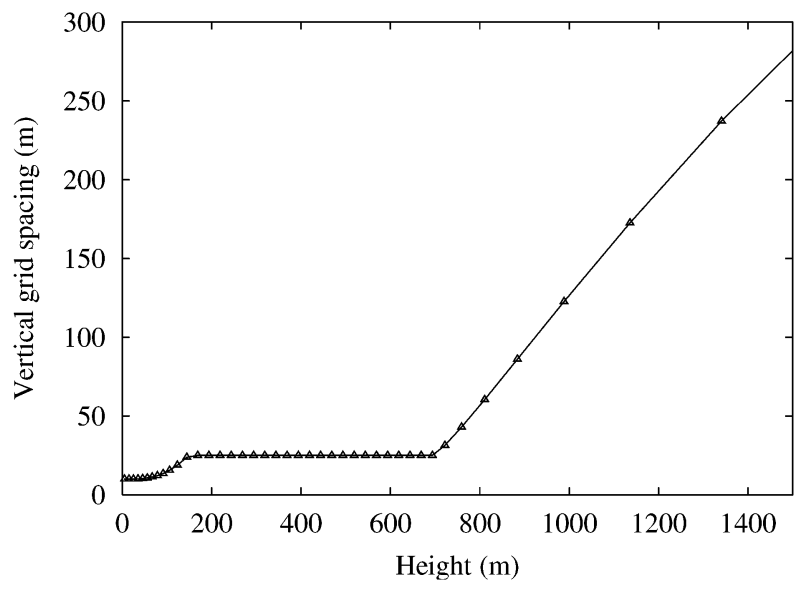

FIG. 2. (a) COAMPS domain configuration for coarse, medium, and fine mesh grids (18, 6, and $2 \mathrm{~km}$ ) for the $25 \mathrm{Jul} 1997$ simulations. (b) Vertical grid spacing as a function of gridpoint height.

water contents characteristic of PBL stratocumulus, the autoconversion threshold of $1.0 \mathrm{~g} \mathrm{~kg}^{-1}$ is not reached and no precipitation forms, meaning the cloud physics scheme is essentially a simple saturation adjustment. In the event that the CCN concentration is very large (a highly polluted air mass), simulations of stratocumulus using the KK and Kessler parameterizations should converge.

The veracity of the entrainment rate computed by the model has been largely neglected in these experiments, partly because there are little data about the inversion structure over the domain and time in question. While acknowledging the fundamental nature of entrainment on boundary layer clouds, our aim is to investigate (a)

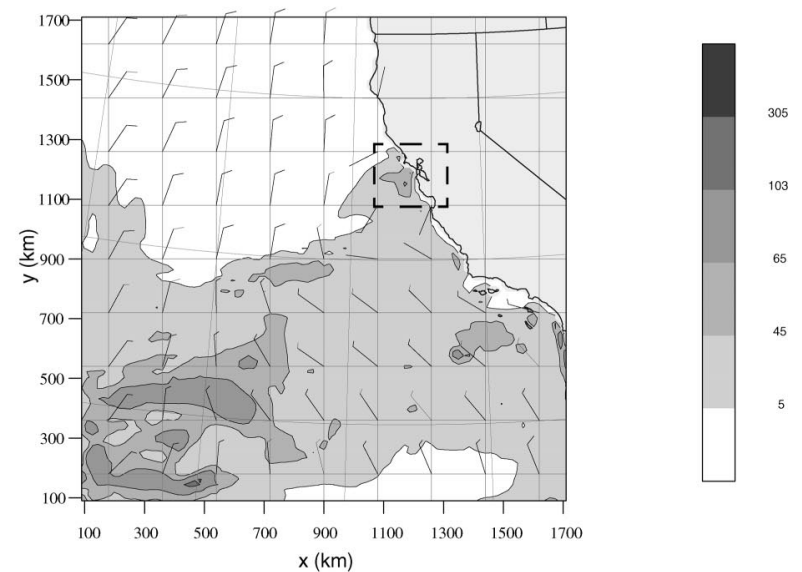

(b)

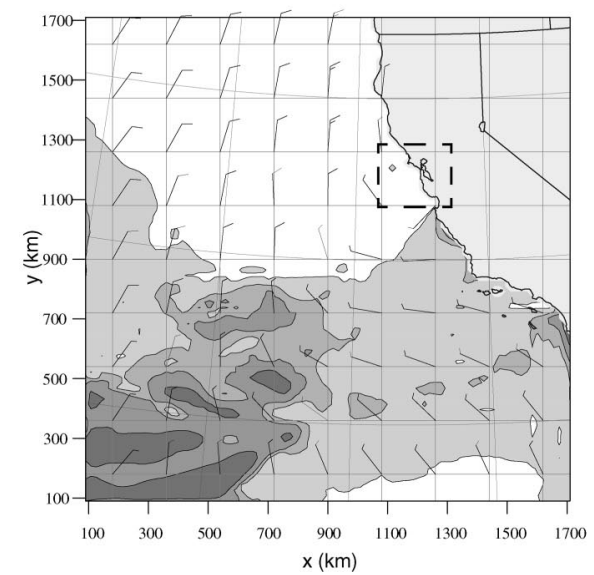

FIG. 3. The 1800 UTC liquid water path $\left(\mathrm{g} \mathrm{m}^{-2}\right)$ for the $18-\mathrm{km}$ simulations: (a) KK, (b) ND. The innermost domain $(\mathrm{Z} \mathrm{km})$ dashed box denotes the San Francisco (northern) and Monterey (southern) Bays.

whether a mesoscale model is able to produce some manner of mesoscale organization with the accompanying transition from stratocumulus to trade cumulus, and then to explore how we might interpret that form in the context of previous LES and observational studies. An increasing understanding of entrainment and its parameterization unquestionably will improve the accuracy of forecasts for boundary layer clouds, but for our purposes a perfect treatment of entrainment is an unnecessary luxury.

\section{Coarse mesh $(18 \mathrm{~km})$ results}

Although the majority of the results presented will be for the fine 2-km mesh, a brief discussion of how the model treats the cloud system at $18 \mathrm{~km}$ will put the fine mesh results into a larger-scale context. Figure 3 
shows that the model's $18-\mathrm{km}$ mesh is doing a reasonable job in representing the stratocumulus cloud system under investigation, when compared to the Advanced Very High Resolution Radiometer (AVHRR) imagery from a similar time (Fig. 1). The simulation captures the wedge-shaped nature of the cloud system and the decrease in cloud fraction west of the Baja California peninsula seen in the AVHRR imagery. A hint of the cellular boundary layer convection is visible over the southwest side of the domain in both cases, where local maxima in liquid water path (LWP) indicate deep regions of liquid water characteristic of the cellular convection. At $18 \mathrm{~km}$, LWP from the ND simulation (Fig. $3 \mathrm{~b}$ ) is quite similar to that in the $\mathrm{KK}$ run. The region of greater variability in the western part of the domain is perhaps more extensive in the ND case, and the northward extent of the cloud system, particularly near the coast, is somewhat less. The KK simulation shows a CTBL in the coastal region near San Francisco and Monterey Bay area (boxed regions), whereas in the ND run that region is clear.

The effect of including drizzle processes on the bulk thermodynamic and energetic properties of the boundary layer is shown in the mean profiles in Fig. 4. Mean profiles are calculated over the fine mesh, using data from the $18-\mathrm{km}$ grid, in order that the resolution dependence be demonstrated. Calculating mean profiles is frequently performed when analyzing LES results, but care must be taken when applying this technique to mesoscale simulations. Unlike LES models, which use periodic boundary conditions, in COAMPS simulations mesoscale signals may enter the calculation domain and possibly overwhelm or mask the effects of interest. Furthermore, features of interest may have only a short residence time in the fine mesh domain.

Although the average surface drizzle rate is very small in the $18-\mathrm{km}$ mesh $\left(<0.01 \mathrm{~mm} \mathrm{~d}^{-1}\right.$ over the averaging region used in Fig. 4), less than a typical value for such a clean case, the effects of drizzle evaporating in the subcloud layer are nevertheless apparent in the profiles of cloud liquid water and total water (Fig. 4a). Values of liquid water at cloud top are not sharp as in typical LES results, simply because the upward slope of the inversion height toward the west smears the cloud top. Entrainment is plainly less in the KK case, though the peak $q_{l}$ values are quite similar in both cases. The increased entrainment in the ND experiment warms the boundary layer (Fig. 4b), resulting in higher saturation mixing ratios and an increase in cloud base for a given PBL vapor content.

Even with such weak drizzle production, the boundary layer has a dynamic response to the evaporation in the subcloud layer. Evaporating drizzle stabilizes the boundary layer, requiring the resolved turbulent eddies to do more work in keeping the boundary layer well mixed. The results of Stevens et al. (1998) imply that a typical LES dynamic response to the increased stratification is that the eddies weaken; so presumably the (a)

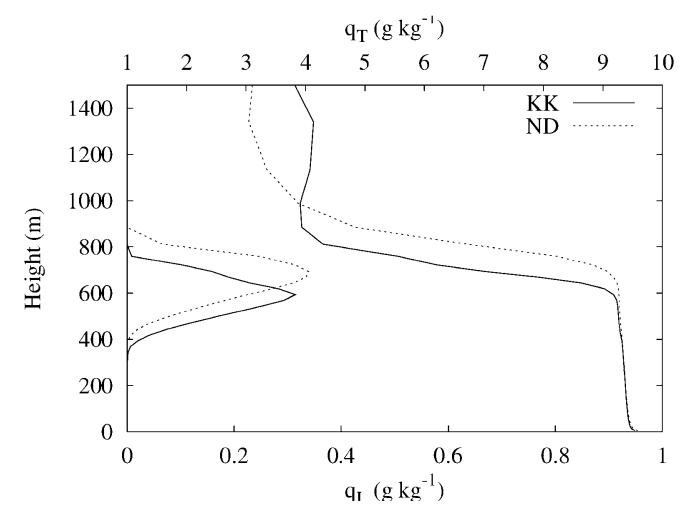

(b)

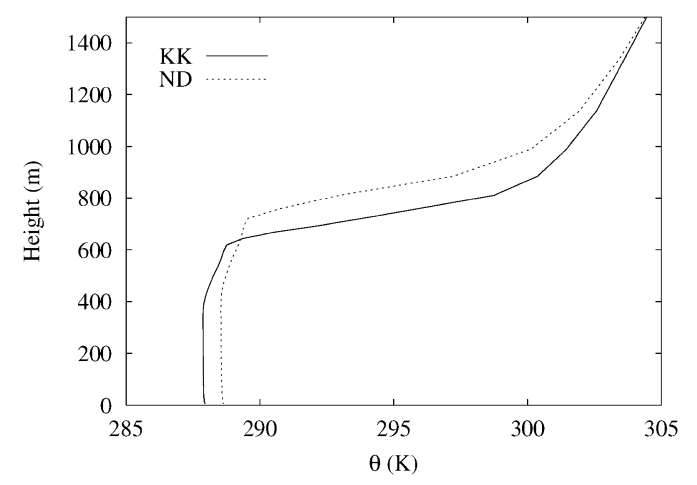

(c)

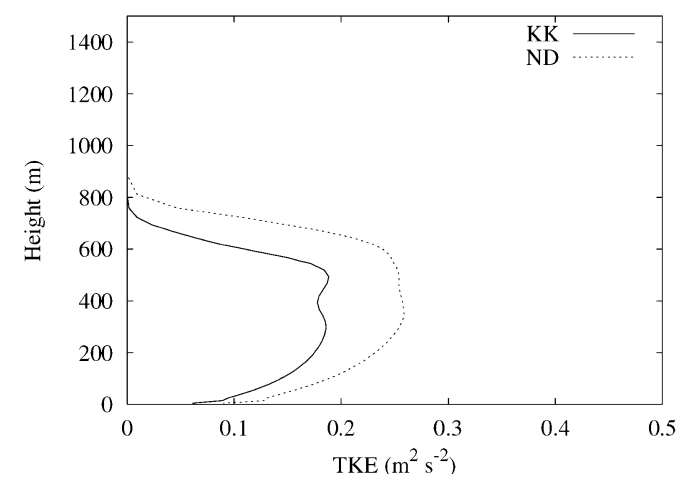

FIG. 4. Mean profiles at 1200 UTC from the $18-\mathrm{km} \mathrm{KK}$ and ND simulations. Profiles were obtained by averaging over the area corresponding to the innermost domain $(2 \mathrm{~km})$ in Fig. 3. (a) Liquid and total water, (b) potential temperature, (c) subgrid-scale TKE.

greater the stratification, the less apt is the boundary layer to be well mixed. Physically, the greater the stratification, the more the diabatic sources are used to try to keep the PBL well mixed and the less is available for kinetic energy for the eddies. Over the 18-km mesh, the boundary layer eddies are assumed to be represented by subgrid-scale processes, and the dynamic response should be evident in the turbulent kinetic energy (TKE) 
field. The TKE profiles in Fig. 4c show that even the weak evaporative cooling in the KK case results in stratification sufficient to significantly suppress the buoyant production of TKE. Although in this situation, weak drizzle has reduced the entrainment and mixed layer TKE, the general relationship between drizzle, entrainment, and boundary layer energetics is often highly nonlinear and counterintuitive. ${ }^{2}$ Moreover, the magnitude of vertical moisture transport modulates the production of drizzle, and the evaporation of falling drizzle can either enhance or suppress TKE depending upon the vertical distribution of the cooling.

\section{Representation of boundary layer processes on the fine $(2 \mathrm{~km})$ mesh}

It is hoped that by scrutinizing the $2-\mathrm{km}$ mesh, the understanding obtained from LES studies can be brought to bear, since the scale difference between a typical LES grid spacing and $2 \mathrm{~km}$ is only one order of magnitude, while that between the LES and typical current NWP meshes may be two orders or more. Interpretation and comparison is still difficult, however, since in the mesoscale model much of the PBL dynamics is parameterized. In any case, understanding the behavior of CTBLs at fine grid spacings is important, since operational NWP grid lengths will be approaching these values.

In addition to the KK and ND experiments discussed above, an additional simulation was made where the cloud droplet number concentration $\left(N_{c}\right)$ is held constant at its initial value throughout the course of the simulation (experiment N0). This quantity is allowed to vary in the KK experiment, where it decreases in response to the growth of drizzle droplets by accretion, nonlinearly increasing $\left(N_{c}^{-1.79}\right)$ the efficiency of subsequent drizzle formation. This process in the KK simulation corresponds physically to the scavenging of small cloud droplets and CCN by the precipitation processes. Holding the number concentration constant allows precipitation to form but not in the nonlinear manner of the KK simulation, so the results are expected to lie between those of KK and ND.

For the comparison between KK, ND, and N0 experiments to be meaningful, the mesoscale signal entering the domain in each of the simulations must be the same. Figure 5 illustrates the experimental configuration used for all simulations. It was decided to perform the KK run on the 18- and 6-km domains, and then only on the $2-\mathrm{km}$ grid compare KK, ND, and N0 results. This procedure makes differences between the three experiments independent of differences in the me-

\footnotetext{
${ }^{2}$ For example, entrainment reduces boundary layer TKE, which subsequently decreases entrainment, implying that the sensitivity to boundary layer parameters might be less than expected (Stevens et al. 1999).
}

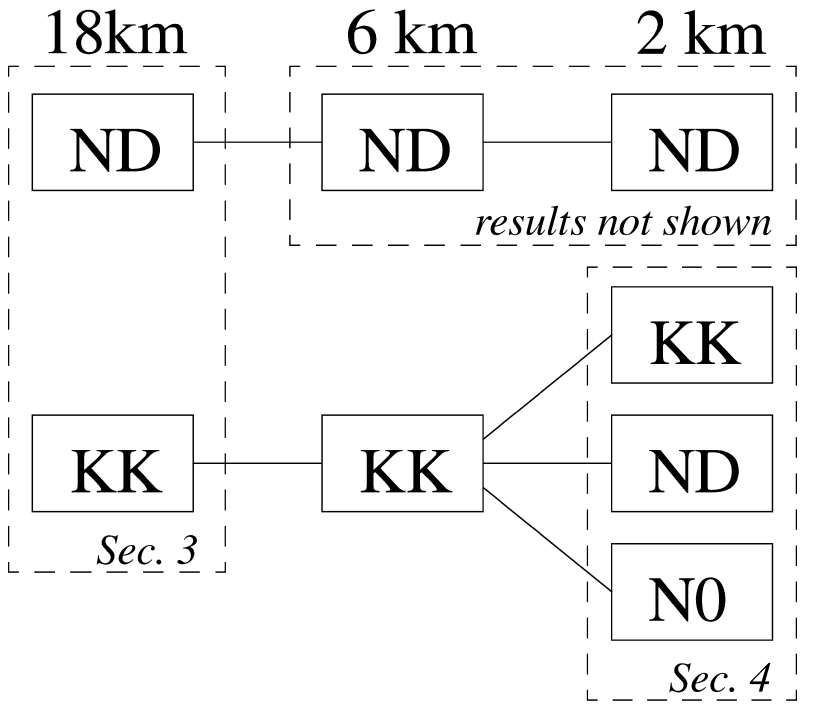

FIG. 5. Schematic of the numerical experiments for the one-way nested grid configuration. Comparison of $\mathrm{KK}$ and ND experiments on the $18-\mathrm{km}$ mesh are discussed in section 3 . The KK, ND, and N0 results on the $2-\mathrm{km}$ mesh, with the parent meshes using the $\mathrm{KK}$ scheme, are presented in section 4 .

soscale signal entering the domain that might arise had we applied the changes on all three meshes.

\section{a. Comparison with SSM/I LWP}

LWP retrievals from the Special Sensor Microwave Imager (SSM/I) covering the 2-km domain have been obtained for 0500 and 1700 UTC. The SSM/I LWP product contains uncertainty of the order of about $10 \%$ for unbroken clouds with an upper bound of $250 \mathrm{~g} \mathrm{~m}^{-2}$ for reliable LWP estimates (Wentz 1989). Probability distribution functions (PDFs) of LWP values from the SSM/I retrievals, KK, and ND are shown in Fig. 6. The N0 experiment is omitted in this case, since its PDF lies between KK and ND. At 0500 UTC (Fig. 6a), the PDFs from both simulations are virtually identical and capture the LWP mode reasonably well compared to SSM/I, but the distributions are too narrow and lack the variability associated with the tail. LWP at 1700 UTC (Fig. 6b) shows a slight difference between KK and ND PDFs, with the mean KK value being slightly smaller. This might be expected, since the drizzle processes in the KK simulation serve as a sink for cloud liquid water, although the decreased drying of the PBL from damped entrainment reduces the difference between the two PDFs. Both KK and ND experiments significantly underestimate the modal LWP compared to SSM/I observed LWP for this time and domain, though the simulations capture the variability better than the 0500 UTC runs.

\section{b. The diurnal cycle and statistics}

The evolution of mean quantities over the $2-\mathrm{km}$ mesh for the KK, ND, and N0 experiments is shown in Fig. 
(a)

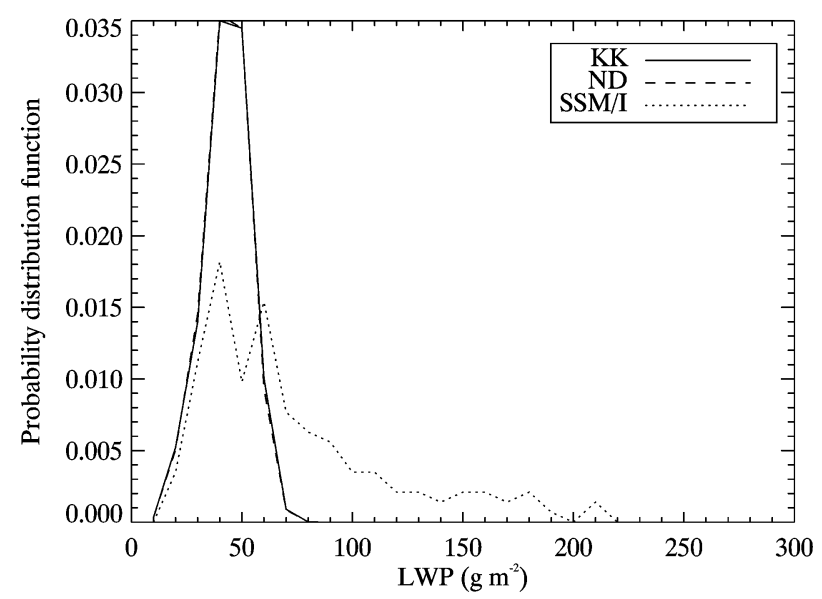

(b)

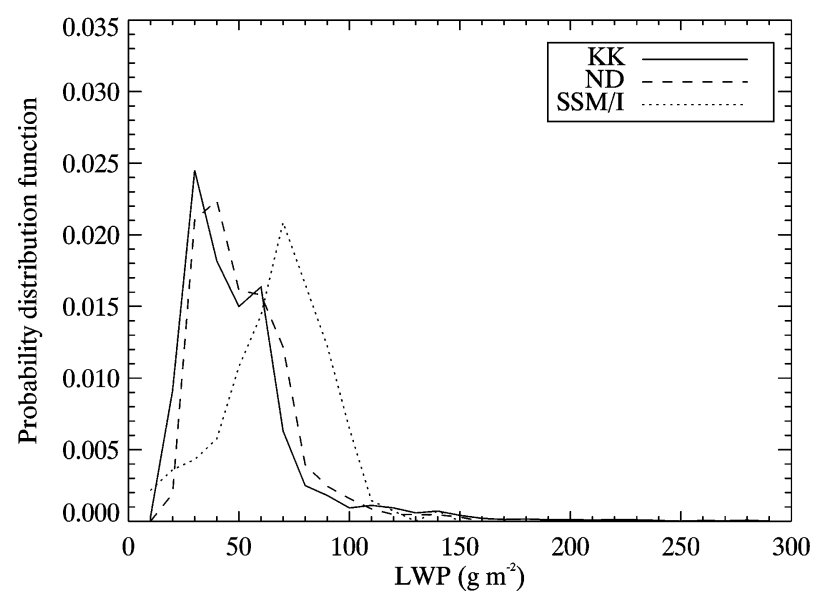

FIG. 6. Probability distribution functions of LWP over the 2-km domain for the KK and ND simulations, and the SSM/I data: (a) 0500 UTC, (b) 1700 UTC. The 0500 UTC PDFs for the two simulations are nearly equal.

7. Because of the sloping nature of the cloud top and inversion, care must be taken when computing mean quantities so that the inversion structure is not diffused by the averaging procedure as it is in Fig. 4. Our solution is to normalize individual columns of cloud water, potential temperature, and mixing ratio by mean cloud-top height, ensuring that the sharp gradient of temperature, moisture, and liquid water present in individual profiles is maintained in the statistics.

Local sunrise and sunset are 1330 and 0327 UTC, respectively, and a diurnal cycle is plainly evident in the rising of the cloud top and inversion from 0000 until 1700 UTC, after which cloud top descends and mean liquid water content (LWC) quickly diminishes. The ascent of the inversion and cloud top before 0800 UTC is a result of boundary condition forcing, while drying of the cloud layer indicated by the descent of the $9 \mathrm{~g} \mathrm{~kg}^{-1}$ contour is indicative of the entrainment process. Moisture rather than temperature is a better indicator of en- (a)

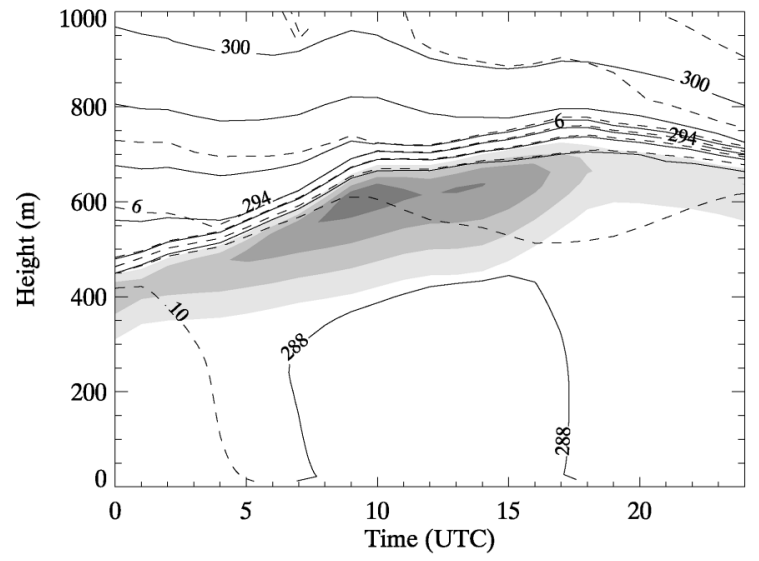

(b)

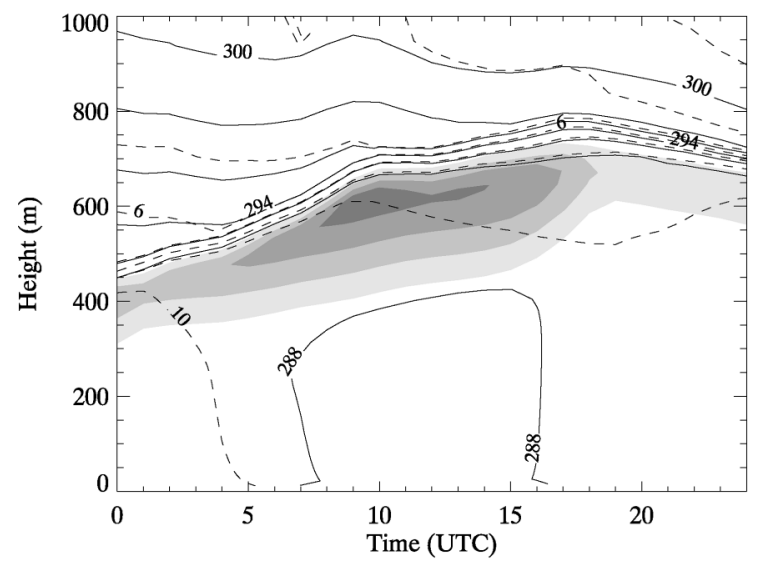

(c)

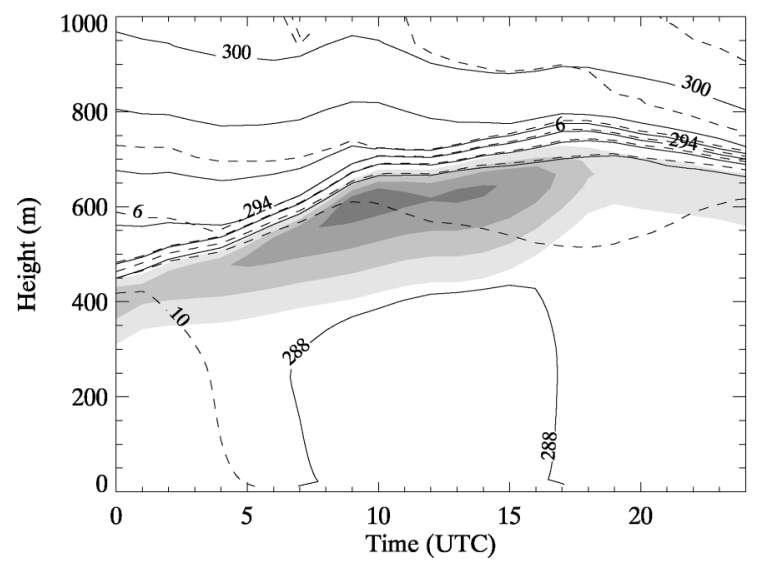

FIG. 7. Evolution of potential temperature (solid), mixing ratio (dashed), and cloud water (shaded, $0.1 \mathrm{~g} \mathrm{~kg}^{-1}$ interval) averaged over the 2-km mesh. The averaging procedure is described in the text: (a) $\mathrm{KK}$, (b) ND, (c) NO. 
trainment in COAMPS, but it is apparent that the PBL grows more slowly after entrainment has brought about a slightly stratified moisture structure, indicating either that entrainment is somewhat self-regulating (Stevens et al. 1999) or that because of the relatively small size of the domain, the residence time of cloudy air over the $2-\mathrm{km}$ mesh places an upper bound on the amount of entrainment a cloudy column experiences prior to exiting the domain.

Figure 7 shows that the evolution of the mean PBL structures in the three experiments are nearly equal. The mesoscale signals entering the $2-\mathrm{km}$ domain in each experiment are equal, and it takes time for the differences in microphysical parameterizations to manifest themselves in the model quantities. The differences between schemes would be greater if the statistics were evaluated only over a downstream subregion of the model grid, but this introduces a complexity of where to subjectively place a calculation grid. Although the mean structure is very similar between the three simulations, Fig. 8 shows pronounced differences in the probability distribution functions of the cloud structure. These figures are composed by making PDFs of LWP at hourly intervals, then stacking them into a threedimensional field and contouring the probabilities. These are in principle very similar to the Contoured Frequency by Altitude Diagram (Yuter and Houze 1995), with the altitude axis replaced by time, and demonstrate the evolution of both the modal LWP and its spatial variability.

Both KK and ND results show an increase in modal LWP from 0000 UTC until approximately 1200 UTC, roughly corresponding to nocturnal conditions. After the sun rises (1330 UTC), the LWP begins to decrease, as it does until 0000 UTC of the following day. This sinusoidal-like pattern in modal LWP for this case is quite similar to the June-July-August (JJA) diurnal climatology derived from two years of Tropical Rainfall Measuring Mission Microwave Imager (TMI) data and represented by the dashed light gray lines in Figs. 8a-c (Wood et al. 2002). For this particular date, the simulation captures the climatological behavior well in phase and maximum diurnal value (at $\sim 1200$ UTC), while the diurnal minimum LWP is somewhat underestimated.

The pronounced tail of the KK distribution from 1700 to 2000 UTC (Fig. 8a) hints at an organized mesoscale variability and corresponds to the development of linear PBL convective features characterized by large values of LWP. In the KK experiment, these organized convective features represent a drizzle-induced transition from unbroken stratocumulus to a boundary layer cumulus regime, a process that does not occur in the ND case. The tail in the KK distribution decreases rapidly after 2000 UTC as the preexisting convection leaves the domain and strong shortwave absorption thins the cloud deck, suppressing subsequent drizzle-induced cumulus. As would be expected, the N0 experiment (Fig. 8c) lies partly between the KK and ND results, since it includes (a)

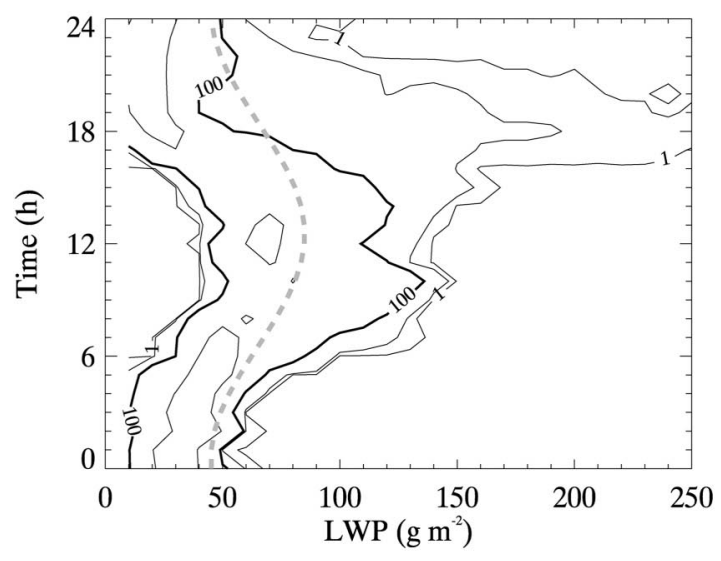

(b)

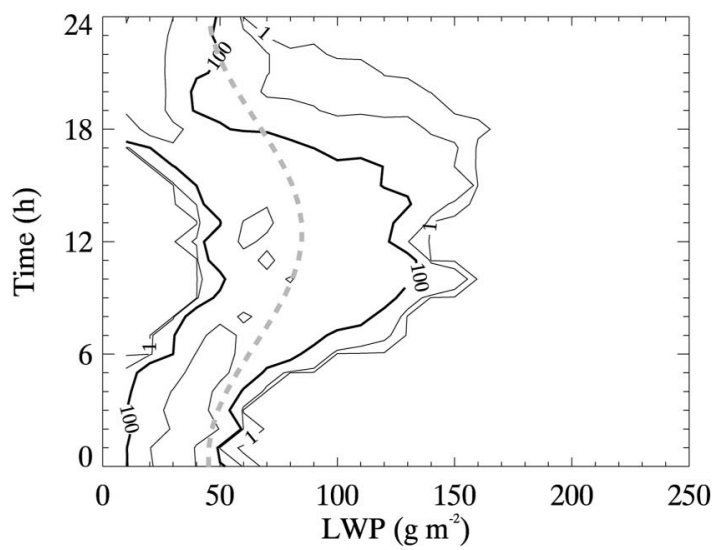

(c)

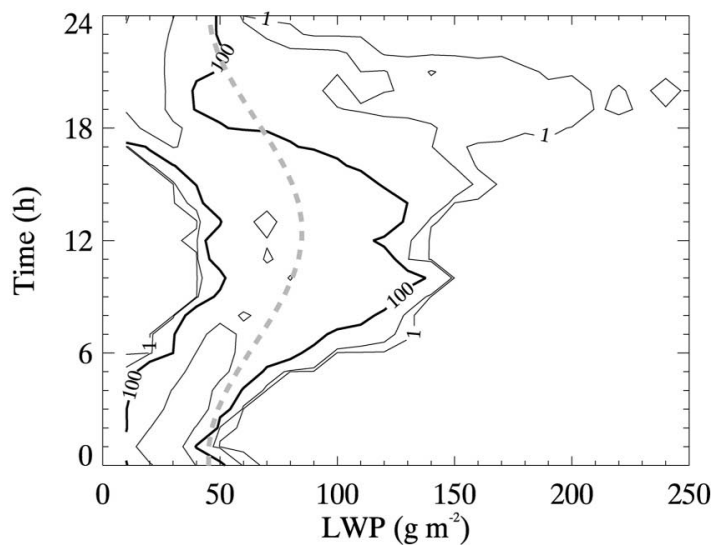

FIG. 8. Evolution of hourly LWP PDFs, composited and contoured on a logarithmic scale. Contour units are $\left[10^{-6} \mathrm{~h}^{-1}\left(\mathrm{~g} \mathrm{~m}^{-2}\right)^{-1}\right]$ : (a) $\mathrm{KK}$, (b) ND, (c) NO. The light gray dashed line represents the TMIderived JJA satellite climatology supplied by Robert Wood [see Wood et al. (2002) for methodology]. 
drizzle effects but not scavenging of cloud droplets and the associated enhancement of drizzle. Notwithstanding the variability arising from the cumulus regime in the KK simulation, the trend in all three experiments is toward more variability during the night, but this result is due more to increased variability imposed by the oneway grid interaction than from intrinsic physical processes over the 2-km mesh.

\section{c. Cloud system spatial structure and evolution}

Although only subtle variations in statistics are evident between the experiments, since the most pronounced dissimilarities take place only over a portion of the $2-\mathrm{km}$ domain, the spatial structure of the simulated fields themselves reveals pronounced differences. Figure 9 compares the 1800 UTC cloud structure for the KK and ND simulations. Compared to the ND LWP in Fig. 9b, the KK cloud field in Fig. 9a is much more variable and characterized by organized quasi-linear features of large LWP located in the southern portion of the domain, aligned nearly normal to the surface wind. The only pronounced structure in the ND LWP field occurs over the southwest corner of the domain, a feature also present in the KK LWP.

Vertical cross sections of $q_{c}$ through the northern and southern parts of the domain in Figs. 9c-f illustrate the cloud structure early and late compared to a column Lagrangian residence time, with the northern cross section representing clouds that have recently entered the domain and the southern section representing clouds that have over the course of several hours traversed the domain and evolved. All the vertical cross sections demonstrate the climatological signal of the inversion sloping upward toward the west responding to increased sea surface temperature. The northern $q_{c}$ cross sections are very similar in both cases, not surprising since the signal entering the 2-km domain from the parent grid was designed to be the same for both KK and ND. A pronounced evolutionary difference is evident by the time the clouds reach the southern part of the mesh, however, as is apparent in Figs. 9e and 9f. While the southern cross section of $q_{c}$ in the ND experiment is very similar to the northern, the $q_{c}$ in the southern region of the KK simulation is vastly different and exhibits a complicated structure in cloud base and top. Pronounced areas of large LWP in Fig. 9a correspond to cloud bases that extend below the stratocumulus cloud deck, while surrounded by regions of thin cloud. Cloud top is strongly variable, higher over regions of significant LWP and lower over the thin cloud regions. The cloud structure in the KK simulation is a representation of a transition from the well-mixed stratocumulus-topped boundary layer toward a broken, boundary layer cumulus regime that is organized in mesoscale bands. This structure may be a mesoscale model analog to the drizzle-induced cloud breakup produced in the large eddy simulation study by Stevens et al. (1998).
PBL vertical velocity (at $z=431 \mathrm{~m}$ ), LWP, and surface plots of wind, drizzle rate, $q_{v}$, and potential temperature at hourly intervals from 1600 to 2000 UTC for the KK simulation are tiled in Fig. 10 and illustrate the development of considerable heterogeneity in the cloud system properties. As previously mentioned, it must be kept in mind that the boundary conditions are not periodic and that over the course of the simulation meteorological signals enter the domain through the inflow boundaries. Little structure is present until the cloud LWC becomes large enough for significant drizzle to form. Beginning at 1600 UTC, regions of resolved updrafts and downdrafts with peak magnitudes in the range of $\pm 0.2 \mathrm{~m} \mathrm{~s}^{-1}$ begin to develop toward the southeast, in bands that are roughly normal to the mean boundary layer flow. A time series of the LWP field confirms what the single time level frame in Fig. 9a implied, namely that the cloud system is at first an unbroken stratocumulus deck, which subsequently evolves to contain convective elements and ultimately, regions of thinning cloud between.

Surface drizzle rate is strongly correlated with LWP such that the thicker clouds produce the most drizzle. Peak drizzle rates are over $6 \mathrm{~mm} \mathrm{~d}^{-1}$, and with typical latent heat flux between 50 and $60 \mathrm{~W} \mathrm{~m}^{-2}$, the model behavior seems reasonable given the observational evidence of Austin et al. (1995) that local precipitation rates can be as much as four to five times larger than the replacement moisture flux. The simulated peak value of $6 \mathrm{~mm} \mathrm{~d}^{-1}$ equates to $174 \mathrm{~W} \mathrm{~m}^{-2}$ in energetic units. Predictably, the surface $q_{v}$ field is also strongly correlated with drizzle, since evaporating precipitation increases the subcloud water vapor content. Evaporating drizzle has a more limited effect on the temperature field, however, with the decrease in surface temperature only able to account for about half of the cooling predicted from the increase in surface $q_{v}$. Weak $(\sim 15 \mathrm{~W}$ $\mathrm{m}^{-2}$ ) surface sensible heat flux, $S$, might explain some of the warming, especially if the subcloud layer is decoupled such that $S$ would be distributed over a comparatively shallow surface layer. It is also conceivable that heating can occur over the broad resolved downdraft regions after the atmosphere becomes stably stratified by evaporated drizzle.

Regions of upward vertical velocity, $w$, are associated with higher values of LWP and stronger surface drizzle rates as are particularly evident in the 1800 and 1900 UTC frames. Drizzle rate and vertical velocity are strongly correlated, but the evolution of LWP lags somewhat changes in $w$. Robust drizzle production and precipitation occur in the updraft regions. Plentiful downdrafts surrounding the resolved strong updrafts arise from mass continuity requirements and are associated with local LWP minima in virtually drizzle-free locations. The drying effect associated with the downdrafts tends to thin the cloud and make that a location particularly unfavorable for drizzle growth. In this manner, 
(a)
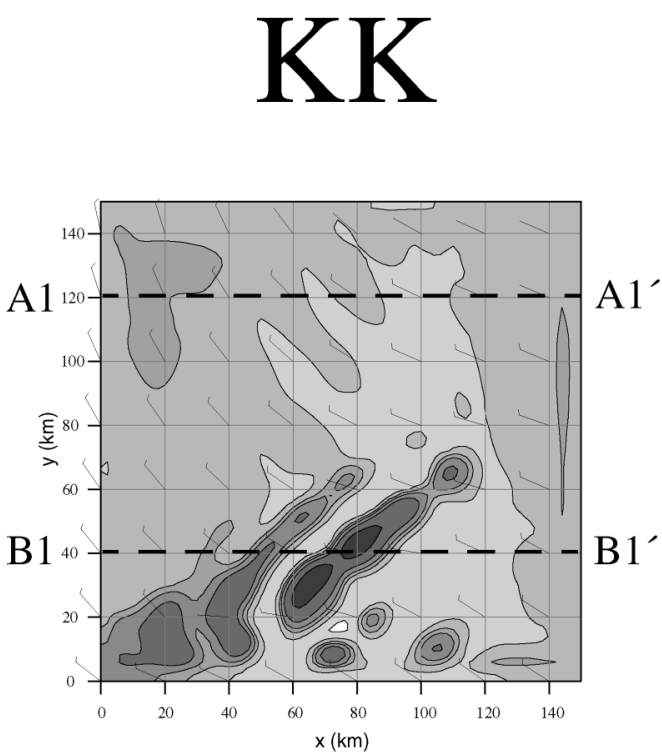

(c)

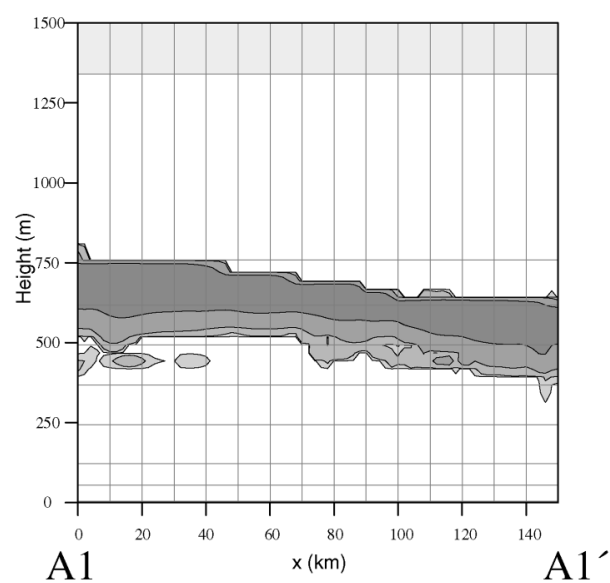

(e)

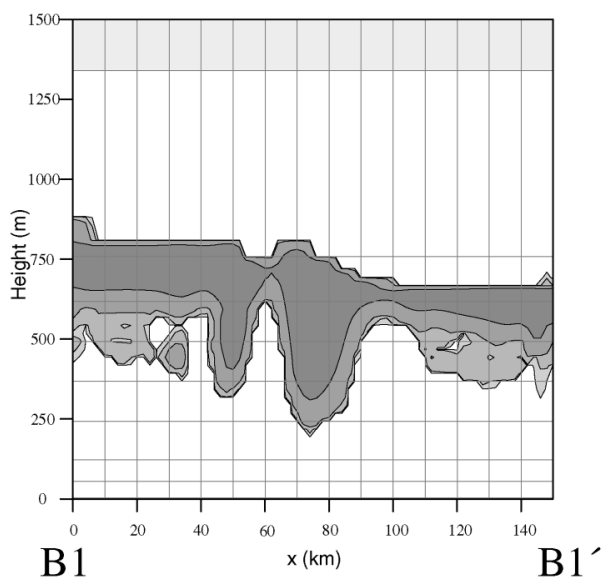

(b)

ND

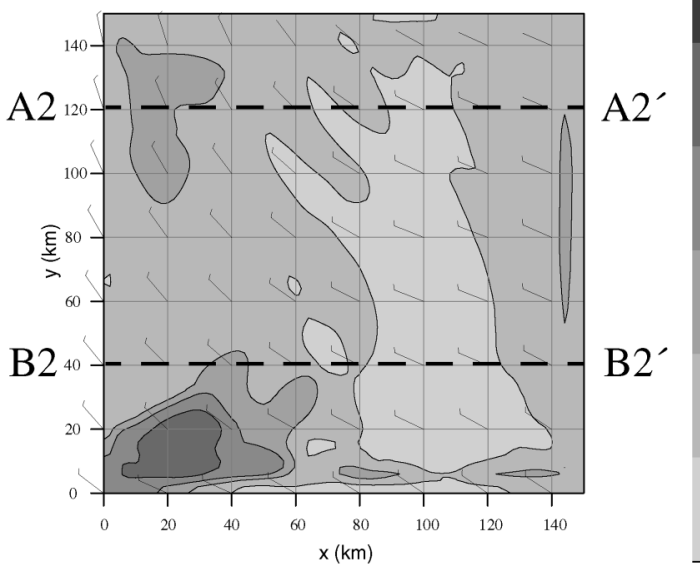

205

105

65

45

25

5

(d)

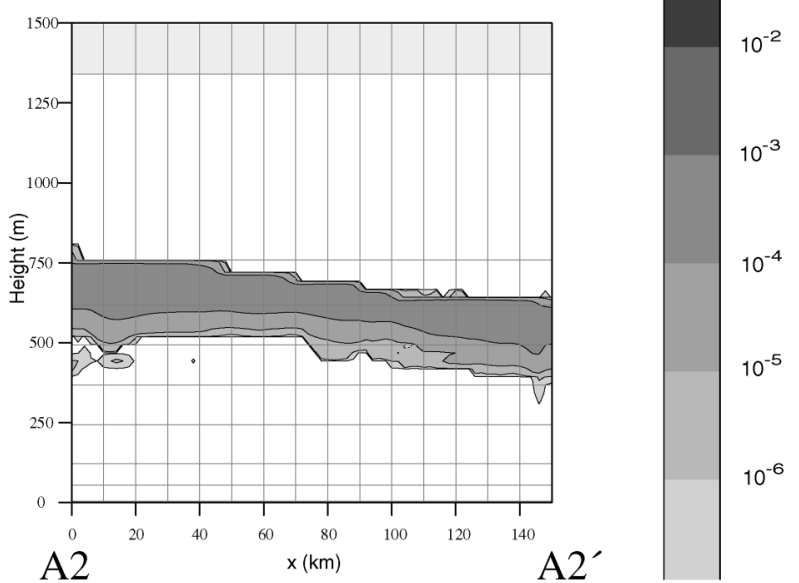

(f)

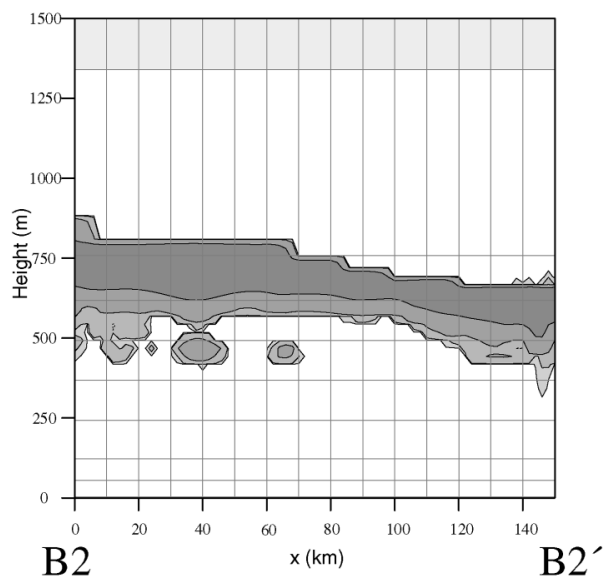

$10^{-2}$

$10^{-3}$

$10^{-4}$

$10^{-5}$

$10^{-6}$ 
both the updraft and downdraft structures contribute to spatial variability of the cloud system.

\section{d. Physical interpretation of the cloud structures}

These simulations develop a significant degree of mesoscale organization in the form of cloud bands 5-20 $\mathrm{km}$ wide and corresponding regions of resolved-scale vertical velocities. The spatial scale of the vertical velocities in the mesoscale model is an order of magnitude greater than those in large eddy simulation, and the magnitudes less by a factor of 10 . Vertical velocity in LES results corresponds to actual boundary layer eddies that are parameterized in the mesoscale model, so how should the dynamic fields be interpreted? The observational study of two cases of closed mesoscale cellular convection (MCC) by Rothermel and Agee (1980) shows a significant mesoscale (low frequency) signal in power spectra of temperature and humidity. Only one of the two cases contains mesoscale energy $(\sim 32 \mathrm{~km})$ in the vertical velocity field, though the authors speculate that strong turbulent fluctuations resulting from a low flight level $(100 \mathrm{~m})$ might mask a subtle mesoscale signal in the second case. The results of their study imply that the most logical approach is to consider the resolved updraft regions in the numerical experiments a mesoscale vertical velocity, representative of the mean upward motion from an ensemble of cloud elements.

The differences in how the dynamic fields are represented in the model dictate that the physical mechanisms of drizzle production in a mesoscale model setting be different from that in an LES model. In COAMPS, drizzle formation is greatest in regions of high LWC, which is itself proportional to the resolved updraft intensity. LES results demonstrate a considerably more complex relationship between regions of drizzle production and vertical velocity structure on a scale an order of magnitude smaller than the finest mesoscale model domain considered in this study. The LES dynamical structure contains large regions of weak downdrafts $\left(<0.5 \mathrm{~m} \mathrm{~s}^{-1}\right.$ in magnitude) interspersed with localized (100-300 m) intense updrafts. Drizzle drops are initially formed in updraft regions and grow there, because they are prohibited by the updraft from falling. Some drops may continue to grow by coalescence even when they are detrained into the descending branch of the circulation, upon which they finally fall below cloud base. COAMPS partially mimics the suspension of drizzle drops by updrafts explicitly resolved in large eddy simulation, although the updraft magnitude is much smaller than in LES results $\left(0.2 \mathrm{vs} 1.0 \mathrm{~m} \mathrm{~s}^{-1}\right)$. The mesoscale model updrafts are a mesoscale representa- tion of the PBL cloud processes and are taken to correspond to the ensemble mean of the actual eddy structure resolved by an LES model.

\section{Transition from stratocumulus to PBL cumulus regime}

LES studies show that substantial evaporative cooling $^{3}$ of drizzle can result in the stabilization of the subcloud layer, resulting in a poorly mixed, stably stratified boundary layer. In the absence of deep boundary layer circulations, the moisture supply to the clouds is temporarily reduced and instead accumulates near the surface, changing the behavior of the system into that of a more cumulus-like regime (Stevens et al. 1998). Although in this stably stratified boundary layer cumulus regime the lack of deep updrafts and downdrafts is commonly labeled a "decoupling" of the cloud and subcloud layers, the two may nevertheless be strongly dynamically linked through the presence of the deep cumulus updrafts, which are a significant moisture source for the cloud layer. Furthermore, these strong cumulus updrafts change the nature of the entrainment process, as the results of Wyant et al. (1997) imply, and may encourage the thinning and breakup of the cloud deck.

Figure 10 shows that the model is capable of developing a significant degree of mesoscale organization by producing a drizzle-induced transition on the mesoscale akin to that produced on smaller scales by large eddy simulation. The broad region of moderate cloudiness at 1600 UTC produces an extensive area of light drizzle, after which lines of deep drizzling cumulus ensembles arise that are oriented normal to the mean boundary layer flow. The cloud bands move with the mean wind, though new bands tend to preferentially form upstream of old ones (cf. 1700 UTC and 1800 UTC). The cloud field never completely breaks apart, though the results at 2000 UTC imply that a field of cumulus ensembles might exist amid cloud-free regions.

The wind field is predominantly northwesterly and contains little vertical shear, so a vertical cross section from northwest to southeast might be thought of as the Lagrangian movement of columns of cloudy air through the domain. Figure 11 shows the conditions on the 2$\mathrm{km}$ domain at 1800 UTC, with the NW-SE line representing vertical cross sections in Fig. 12. The cross sections roughly mimic the path of the cloudy columns as they enter the domain, lightly drizzle, and subse-

\footnotetext{
${ }^{3}$ We say "substantial" because weak drizzle might evaporate just below cloud base, thereby increasing the instability for surface-based parcels (see Feingold et al. 1996 and Jiang et al. 2002).
}

FIG. 9. Comparison of 1800 UTC LWP $\left(\mathrm{g} \mathrm{m}^{-2}\right)$ and $q_{c}\left(\mathrm{~kg} \mathrm{~kg}^{-1}\right)$ for (left) KK and (right) ND experiments: (a) KK LWP, (b) ND LWP. (c) and (d) Vertical cross section of $q_{c}$ along northern line indicated in (a) and (b). (e) and (f) Vertical cross section of $q_{c}$ along southern line indicated in (a) and (b). 


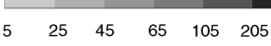

(a)
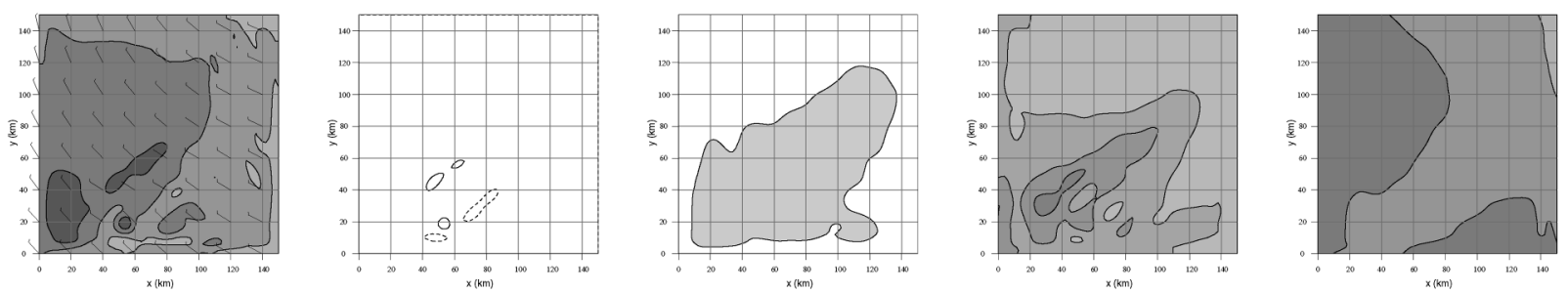

(b)
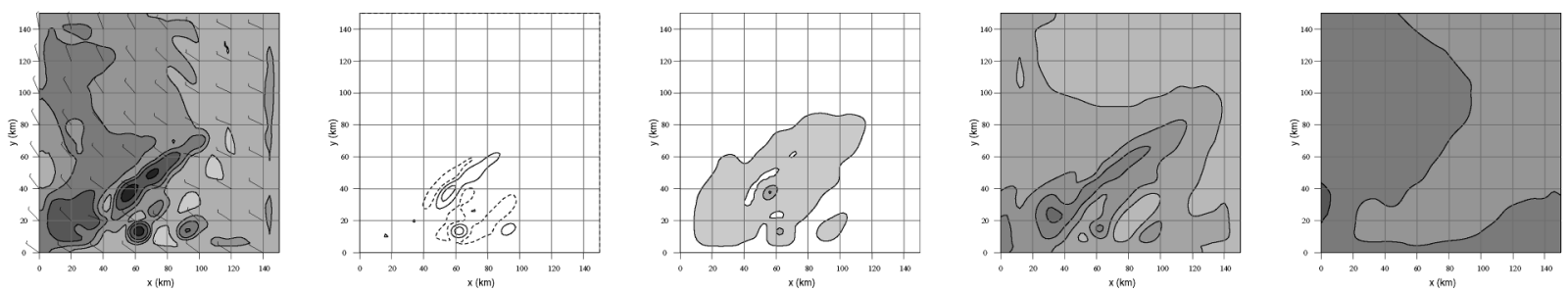

(c)
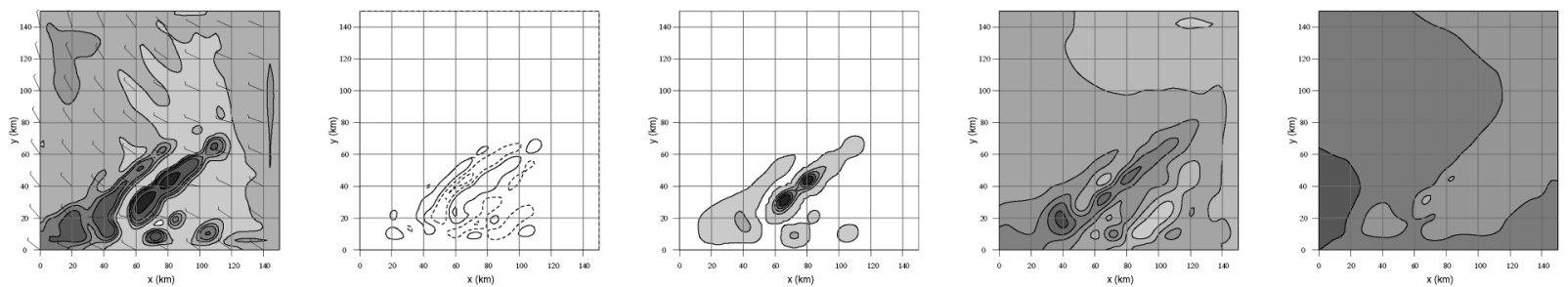

(d)
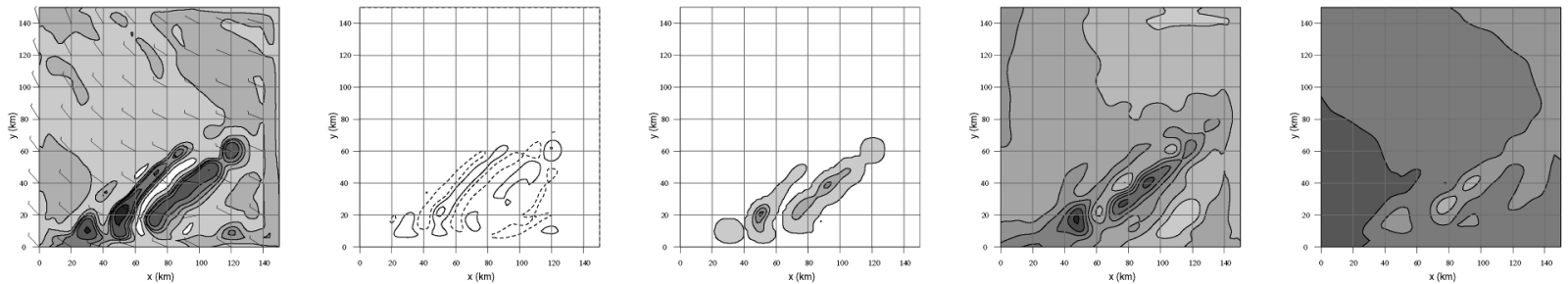

(e)
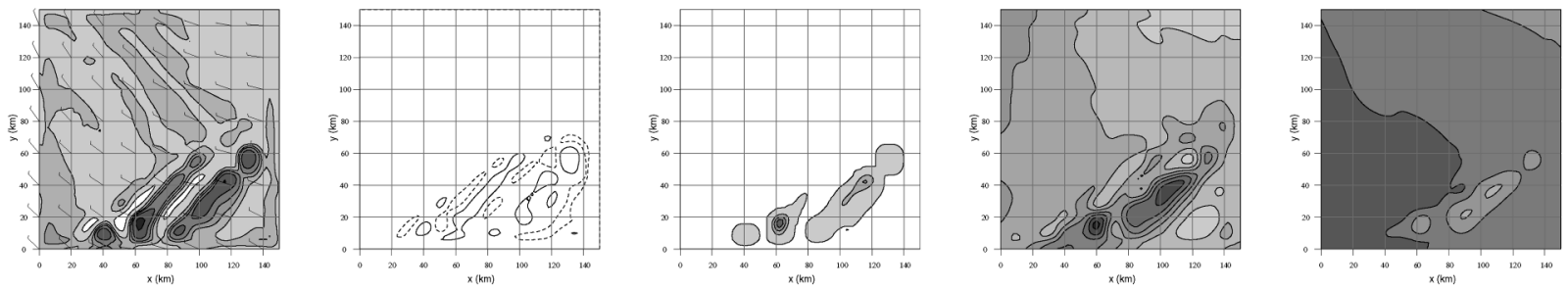

FIG. 10. Columns of (far left) LWP $\left(\mathrm{g} \mathrm{m}^{-2}\right)$, (middle left) vertical velocity at a height of $431 \mathrm{~m}$ (contour intervals of $0.1 \mathrm{~m} \mathrm{~s}{ }^{-1}$ ), (middle) surface drizzle rate $\left(\mathrm{mm} \mathrm{d}^{-1}\right)$, (middle right) surface vapor mixing ratio $\left(\mathrm{g} \mathrm{kg}^{-1}\right)$, and (far right) surface potential temperature (K) at hourly intervals from (a) 1600 UTC to (e) 2000 UTC. 
(a)

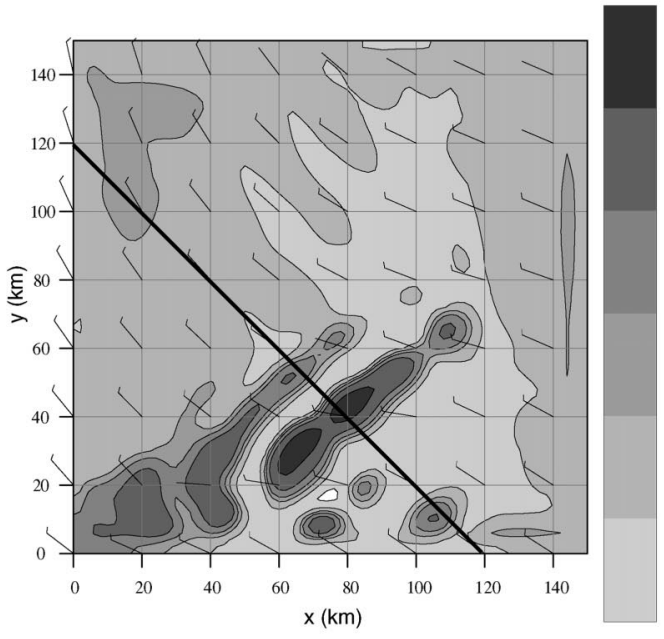

(c)

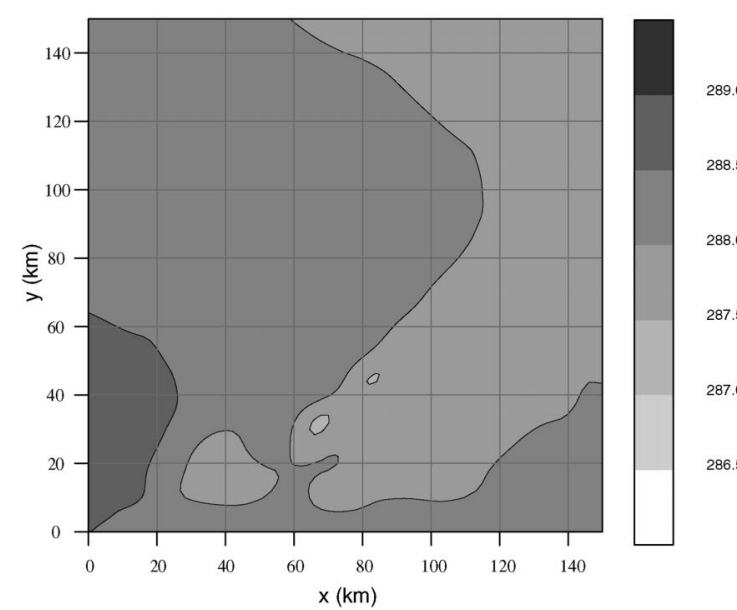

(b)

205

105

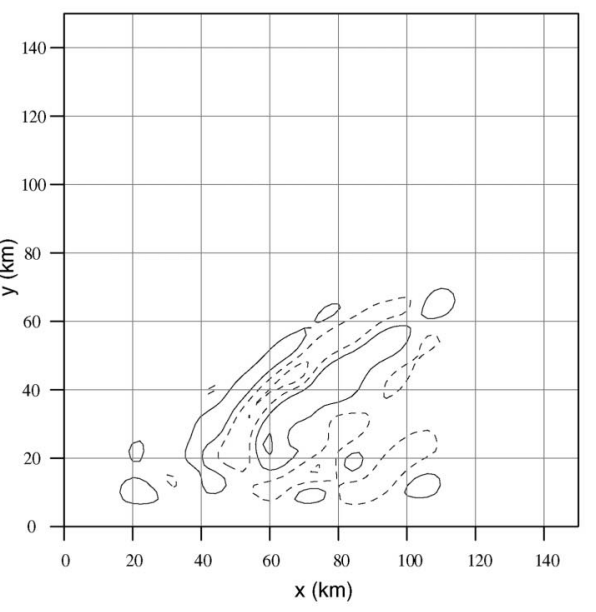

(d)

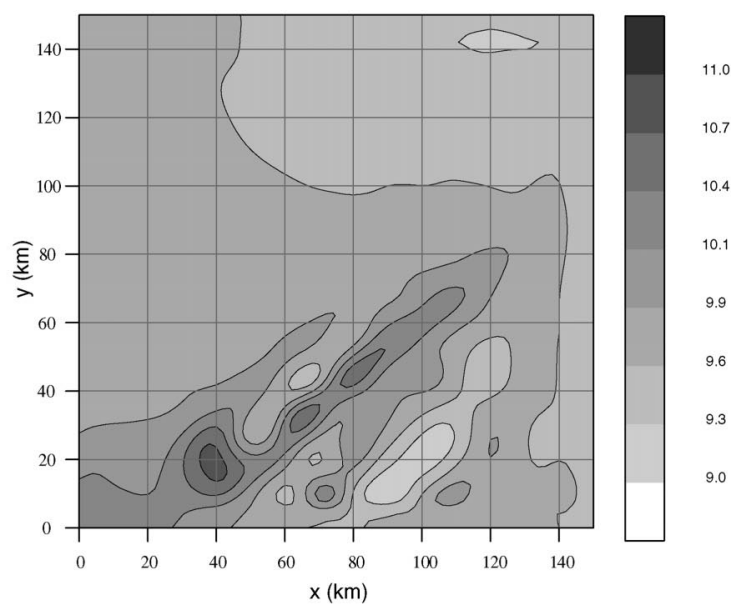

FIG. 11. The 1800 UTC boundary layer quantities: (a) LWP $\left(\mathrm{g} \mathrm{m}^{-2}\right)$, (b) vertical velocity (contour intervals of $0.1 \mathrm{~m} \mathrm{~s}^{-1}$ ) at a height of $431 \mathrm{~m}$, (c) surface potential temperature $(\mathrm{K})$, (d) surface water vapor mixing ratio $\left(\mathrm{g} \mathrm{kg}^{-1}\right)$. The dark line in (a) oriented northwest-tosoutheast represents vertical cross sections shown in Fig. 13.

quently transition into a boundary layer cumulus regime. This perspective is not perfect, however, since the Lagrangian interpretation of these vertical cross sections is corrupted by the fact that mesoscale signals enter the $2-\mathrm{km}$ mesh, and thus the cross sections do not represent the temporal evolution of similar columns of air but the evolution of columns with different initial properties.

Although these cross sections are not perfect substitutes for a thorough trajectory analysis, they show development of significant structure in the thermodynamic fields as columns of PBL air traverse the domain. Bolded contours of $292 \mathrm{~K}, 290 \mathrm{~K}$, and $8 \mathrm{~g} \mathrm{~kg}^{-1}$ in Figs. 12a, $12 \mathrm{c}$, and $12 \mathrm{~d}$, respectively, are associated with the base of the inversion. The potential temperature structure of the subcloud layer is rather well mixed from the boundary to the strong drizzle core at $115 \mathrm{~km}$ (Fig. 12c), while these strong regions of drizzle are associated with greater moisture stratification and an increase in surface water vapor (Fig. 12d). The strongest regions of drizzle correspond to low cloud bases and resolved upward vertical motion, as illustrated in Fig. 12e. The cooling and moistening in these convective regions arises from evaporation of falling drizzle, since the low-level moisture increase in Fig. 12d is accompanied by cooling in Fig. 12c. Throughout the cloud layer, liquid water virtual potential temperature $\left(\theta_{\mathrm{v} 1}\right)$ appears nearly constant, as it should for a well-mixed PBL. However, equivalent potential temperature $\left(\theta_{e}\right)$ is rather stratified, decreasing 
(a) $\theta_{v l}$

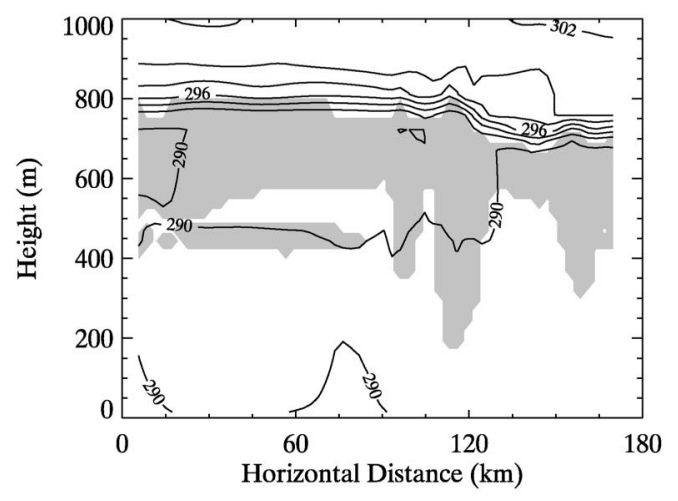

(c) $\theta$

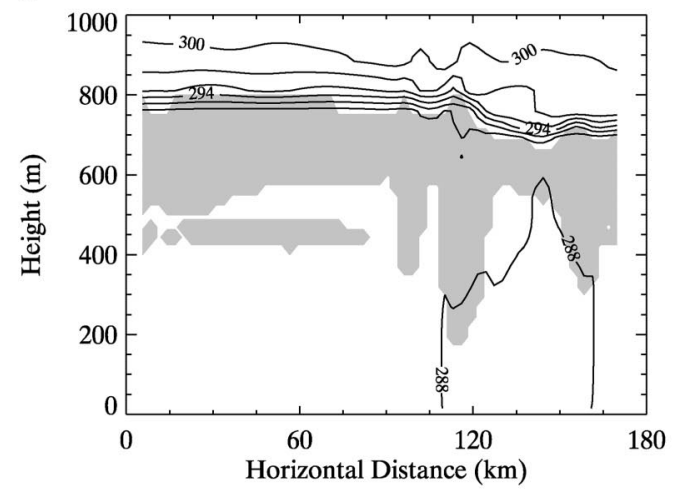

(e) $w$

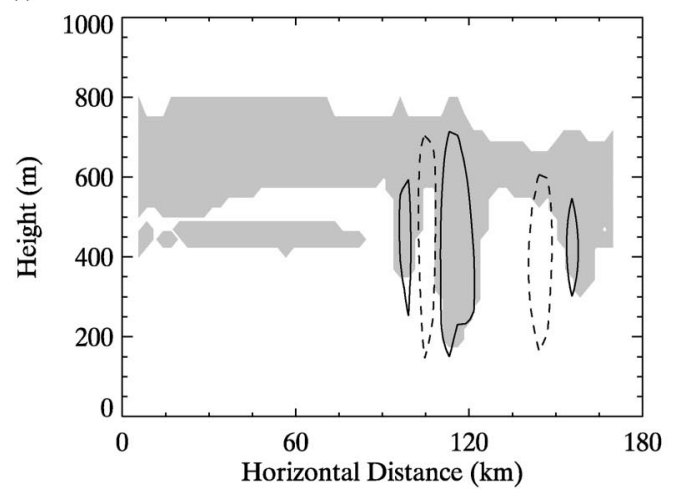

(b) $\theta_{e}$

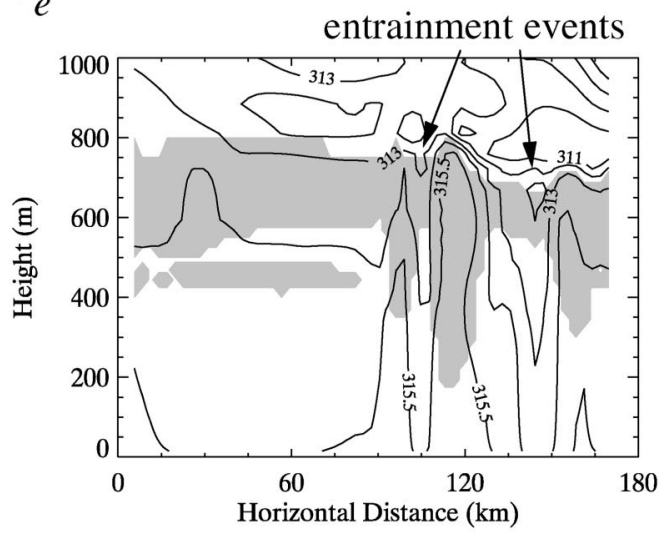

(d) $q_{v}$

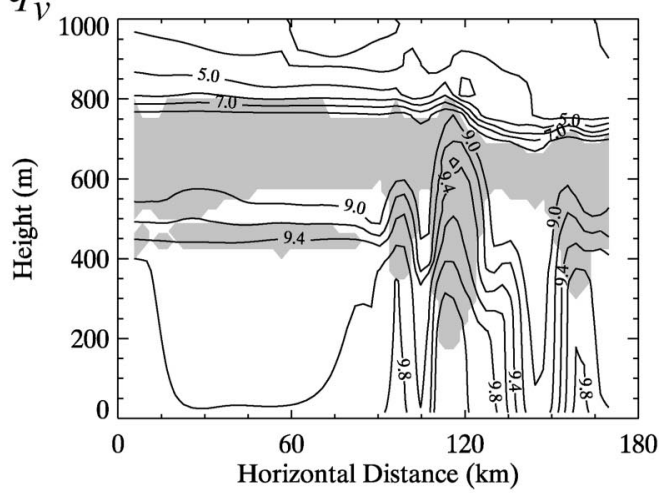

(f) Divergence

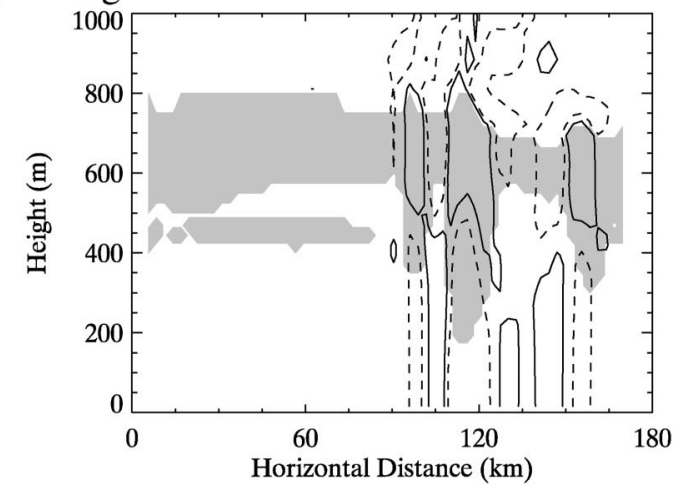

FIG. 12. The 1800 UTC vertical cross sections of model thermodynamic and dynamic quantities taken along the northwest-southeast cross section in Fig. 12: (a) $\theta_{\mathrm{vl}}(\mathrm{K})$, (b) $\theta_{e}(\mathrm{~K})$; contour interval is $1 \mathrm{~K}$ except for $315.5-\mathrm{K}$ level, (c) potential temperature (K), (d) water vapor mixing ratio $\left(\mathrm{g} \mathrm{kg}^{-1}\right)$, (e) vertical velocity (contour values of $\pm 0.05 \mathrm{~m} \mathrm{~s}^{-1}$ ), (f) divergence (contour values of $\pm 10^{-4} \mathrm{~s}^{-1}$ ). The presence of cloud water (thresholded on $10^{-4} \mathrm{~g} \mathrm{~kg}^{-1}$ ) is indicated by light shading.

nearly $2 \mathrm{~K}$ over the 350 -m cloudy layer. The decreasing of $\theta_{e}$ with height satisfies the condition for potential (convective) instability such that a finite displacement of the layer will lead to buoyant free ascent.

Although relatively unused in the CTBL literature (except for Lilly 1968), we include $\theta_{e}$ in our discussions because it is frequently used as a parameter in deep convective circulations and would seem to be appro- priate for a stratified boundary layer with moisture pooling in the surface layer. Here, $\theta_{e}$ should be invariant under conditions of evaporating drizzle, implying that it can only evolve through advection, turbulence, and diabatic processes. In these simulations, weak horizontal gradients predominate, but strong vertical mixing of resolved and parameterized boundary layer eddies, as well as the diabatic processes of radiation and surface fluxes, 
(a)

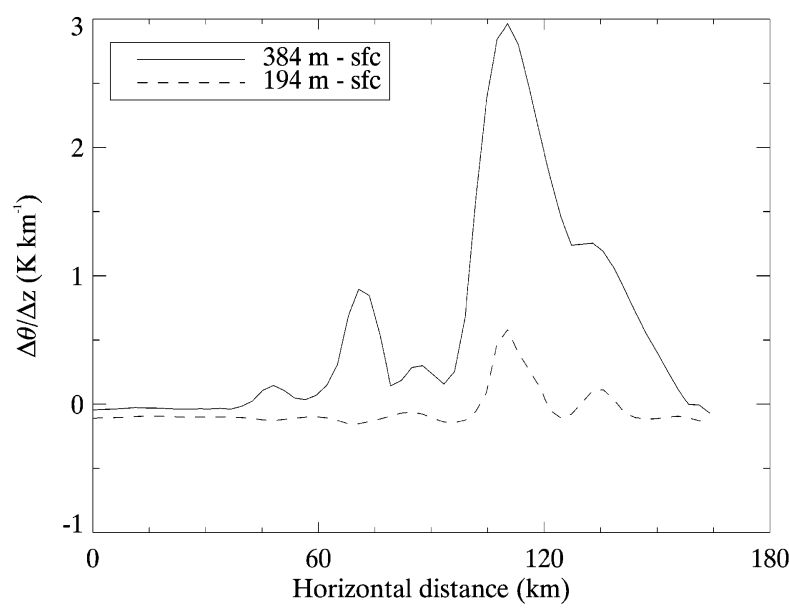

(b)

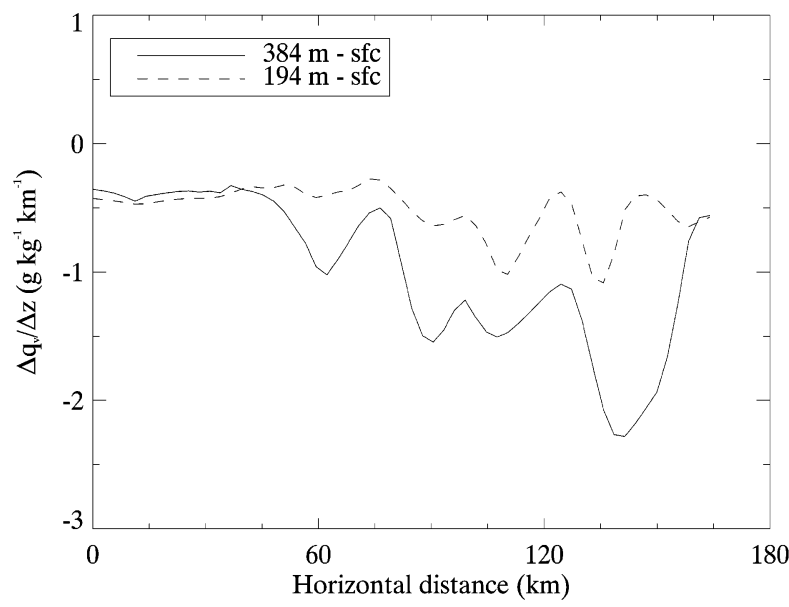

FIG. 13. Measures of stratification between the surface and two levels, 384 and $194 \mathrm{~m}$, for the cross sections in Fig. 13. (a) Potential temperature stratification, (b) water vapor stratification.

can significantly modify $\theta_{e}$. The $\theta_{e}$ stratification here might be thought of as an analog to the deep convective situation of a moisture-rich PBL underlying a capping inversion. Figure $12 \mathrm{~b}$ shows a steady increase in surface $\theta_{e}$ near $75 \mathrm{~km}$ in a region outside any strongly drizzling core. This increase is accompanied by an increase in surface $q_{v}$ but no significant signal in temperature, indicating that moisture from the surface flux is not at this point being efficiently mixed throughout the depth of the PBL. Simple stability parameters along the cross section are shown for the subcloud layer in Fig. 13. In regions that are not well mixed, the temperature stratification across the layer can be significant. The decoupled, convective regime is plainly evident, with slightly stable temperature profiles and moisture pooling at low levels.

To realize potential instability, a finite perturbation is required. The form of the perturbation that triggers the initial cumulus development is difficult to ascertain, but the trigger for subsequent development is evidently tied to the downdraft structure. The thermodynamic structure in Fig. 12b, with low-level $\theta_{e}$ increasing over time, leads to the resolved buoyant motions in Fig. 12e, weak ensemble updrafts and downdrafts. As stated previously, the updrafts are associated with thicker convective towers and promote drizzle growth, while the downdrafts are conducive to drizzle-free areas and cloud thinning. The horizontal divergence (Fig. 12f) reflects the pattern of updrafts and downdrafts but also implies this mechanism for cell propagation. New updraft cells appear to form on the edges of the compensating downdrafts. These downdrafts produce localized regions of surface divergence, as air moving downward spreads laterally. The leading edge of this horizontally spreading air is characterized by convergence, which serves to trigger new updrafts. This mechanism is akin to the explanation of convective squall line propagation, where evaporative cooling produces strong downdrafts and associated surface divergence, which subsequently triggers new cellular development at the edge of the cold pool. By this triggering mechanism, the pattern of updrafts and downdrafts may laterally spread, as it does over the course of the simulation.

An observational study by Jensen et al. (2000) views precipitating PBL clouds in a similar vein, with a preferential triggering of new boundary layer cumulus on the downstream side of existing clouds. They found the triggering to be tied to thin $(\sim 100 \mathrm{~m})$ cold pool regions arising from evaporated drizzle, which under heat and moisture fluxes recover over a period of $\sim 3.5 \mathrm{~h}$. Their observed enhancement of low-level moisture may have explained a stratification of $1 \mathrm{~g} \mathrm{~kg}^{-1}$ in $q_{v}$ over the depth of the subcloud layer, a feature our experiments exhibit as well (Fig. 13b). Jensen et al. argue that the recovered cold pools, with their significant vapor content, will have higher values of $\theta_{e}$, lower LCLs, and are thus perfectly preconditioned to feed new PBL cumulus. Many aspects of our numerical experiments using a mesoscale model agree with this perspective of boundary layer cumulus.

The model produces a stratocumulus cloud field in which $\theta_{\mathrm{vl}}$ is nearly well mixed throughout the depth of the PBL, while significant stratification accompanies $\theta_{e}$ just above cloud base (Fig. 12b). This discussion is complicated by a slight preponderance for multiple cloud layers. Here, $\theta_{e}$ is largely well mixed throughout the depth of the main cloud layer, only becoming stratified again near cloud top. Individual vertical profiles (not shown) reveal that the vertical gradient in $\theta_{e}$ arises from stratification in the water vapor field beginning at the base of the "scud" layer and provide a subtle indication of decoupling of the cloud and subcloud layers. The water vapor field (Fig. 12d) reflects this in the sharp gradient through the scud layer and a more gentle dropoff above, whereas water vapor decrease with height in a well-mixed PBL would be more gradual. These results 
indicate that $\theta_{e}$ may be a better tool than $\theta_{\mathrm{vl}}$ for detecting subtleties in the vertical thermodynamic structure.

One drawback to the type of SGS scheme used in the model is that the development of the convective elements associated with the mesoscale variability first occurs on the resolved scales. It might be expected that the first evidence of the transition would be experienced in SGS fluxes, since physically the development of the cumulus elements occurs on the cloud scale. However, because the slight stratification caused by drizzle evaporation suppresses buoyant TKE production and SGS fluxes, there is no way the SGS scheme can represent the convective aspect of the circulation. Because the grid spacing used here is relatively fine $(2 \mathrm{~km})$, this inconsistency does not appear to be particularly detrimental; however, it may be one reason for the lack of a transition on the $18-\mathrm{km}$ mesh. This problem might be overcome by adding to the model a shallow cumulus parameterization such as the entraining plume model of McCaa and Bretherton (2003a, manuscript submitted to Mon. Wea. Rev.).

Figures $12 \mathrm{~b}$ and $12 \mathrm{e}$ illustrate another process that these experiments exhibit—a kind of explicitly resolved entrainment, though different from that brought about by actual eddies in large eddy simulation. Since $\theta_{e}$ is nonmonotonic, it is a less than ideal variable for deducing entrainment. That said, Fig. 12b shows entrainment events associated with the resolved downdrafts in Fig. 12e, where free tropospheric air of flow $\theta_{e}$ is drawn into the boundary layer from above, while air of larger $\theta_{e}$ in the boundary layer itself is displaced upward. The cloud depths in updraft and downdraft regions reflect the entrainment process, with the thinning cloud deck accompanying entrainment of free tropospheric air. Similar to the discussion of ensemble updrafts in section $4 \mathrm{~d}$, it is fitting to ask what physical process this type of entrainment might represent. Fiedler (1984) introduced the idea of mesoscale entrainment instability, an ensemble analog to cloud top entrainment instability, in an attempt to explain the horizontal scale of MCCs. The convective ensembles in these experiments are organized in bands $\sim 15-30 \mathrm{~km}$ wide in a boundary layer 700-800 m deep (Figs. 11 and 12), which agrees reasonably well with the 30:1 aspect ratio for Fiedler's most unstable mode. The mesoscale entrainment in our results does appear to amplify or exaggerate further the cellular structure of the cloud field. However, the entrainment mechanism in these simulations is more purely mechanical in nature-resolved vertical motions interacting with the entrainment interface-rather than the complicated correlation between mesoscale buoyancy fluctuations and entrainment flux of Fiedler, which has been shown to be applicable only for a weak inversion and a highly stratified free troposphere (Rand and Bretherton 1993).

A relationship exists between cloud base and updraft and downdraft elements, just as in the LES results of Stevens et al. (1998). In the LES study, the presence of drizzle leads to downdraft bases being located higher than updraft bases. Drizzle reduces the LWC of updraft parcels, and after being detrained into surrounding downdraft regions, they descend and become subsaturated at a level higher than the original updraft parcels (see the conceptual model in Fig. 14 of Stevens et al. 1998). The mesoscale model similarly produces low cloud bases associated with the strongest drizzle in the updraft regions and thinner cloud in the downdraft areas. The cause of the thinning appears to be related to the mesoscale effect of dry air above the inversion being entrained into the cloud layer rather than the thinning (asymmetry) mechanism of the LES results. The resolved updraft and downdraft elements in the mesoscale model are not analogous to the eddy structures in the LES, so it is not surprising that the asymmetry behavior is not produced.

\section{Conclusions}

Many previous studies have explored in idealized settings the transition from stratocumulus to the convective boundary layer (trade cumulus) regime, but studies exploring the representation of this process in regional forecast models have been much rarer. Increasing computer power will in the near future enable operational organizations to run at horizontal grid spacings of 2-3 $\mathrm{km}$ over subtropical maritime regions. These grid spacings are more than an order of magnitude larger than those typically used in large eddy simulation and span somewhat of an awkward range, since the eddies themselves are parameterized while organized ensembles of eddies are at least partially resolved. In these experiments, PBL dynamics are almost entirely subgrid for unbroken well-mixed stratocumulus, while resolved vertical motions accompany the boundary layer cumulus regime.

Coarse mesh results $(18 \mathrm{~km})$ in this study fail to develop the mesoscale organization that emerges on the $2-\mathrm{km}$ mesh and show only a subtle sensitivity to pronounced variations in the microphysical parameterization, the most pronounced change being the horizontal location of the cloud boundary. The differences between experimental results likely arise from the effect on entrainment of drizzle and its influence on the parameterized energetics ultimately related to differences in the formulation of the microphysical processes. The inability of the $18-\mathrm{km}$ mesh to develop any significant degree of mesoscale organization implies that a shallow cumulus parameterization would be a useful addition to the model.

While nearly all of the boundary layer processes are parameterized over the $18-\mathrm{km}$ grid, the $2-\mathrm{km}$ fine mesh contains both parameterized and explicitly resolved processes. The unbroken stratocumulus, driven energetically by strong cloud-top cooling and to a lesser extent, surface fluxes, is kept well mixed by the subgrid scheme. In the case of no drizzle, cloudy columns of air pass 
completely through the domain, with thermodynamic quantities remaining nearly well mixed. In the drizzling experiment, on the other hand, drizzle evaporating in the subcloud layer changes the character of the boundary layer sufficiently to allow a slight pooling of high $\theta_{e}$ air just above the surface. The instability associated with this slight CAPE is subsequently realized through resolved updrafts, which are associated with the strongest drizzle production. Compensating downdrafts seem to be able to trigger new upward vertical motion on their periphery, resulting in the initiation of cumulus ensembles in adjacent regions. Previous modeling studies have produced a transition that occurs over a period of days by steadily increasing SSTs, while for the rapid transition $(\sim 6 \mathrm{~h})$ occurring in our model, the presence of drizzle is vital. The most significant aspect of this study is the emergence of organized mesoscale structure in the form of cloud bands that accompanies the transition.

On simple physical grounds, the KK parameterization is clearly more appropriate for marine stratocumulus than the Kessler scheme, which was developed for precipitating continental cumulus clouds. It may seem a tautology to say that the effects of drizzle in a model necessitate a drizzle parameterization, but such is the case. The standard Kessler parameterization seems incapable of bringing about the PBL transition demonstrated in previous studies by large eddy simulation and by COAMPS in these experiments, so use of the KK parameterization should lead to better forecasts of marine stratocumulus. It is noted, however, that for a forecast, radiative transfer and SGS issues may play as strong a role as the microphysical parameterization.

We sought to test the sensitivity of model results to changes in the fundamental treatment of microphysical processes and showed that drizzle can have a pronounced impact on bulk boundary layer properties at grid spacings on the order of $2 \mathrm{~km}$. The impact of changes in microphysical schemes was much more subtle on the parent grids. One likely reason for this is that the greatest drizzle production is occurring in the resolved updrafts on the 2-km grid, while these updrafts are not present on the coarser meshes where very little drizzle is produced. Over the coarse meshes, drizzle arises through autoconversion and begins immediately falling, accreting cloud droplets on the way down through the cloud. The updrafts in the 2-km mesh, however, represent ensembles of boundary layer eddies, which serve to suspend small drizzle droplets, enabling them to grow to larger size, until at last their terminal fall speed is greater than the updraft velocity or they are detrained into adjacent downdraft regions. Feingold et al. (1996) have found this issue of in-cloud residence time to be an important factor in large eddy simulation drizzle production. This process is at least partially represented by the small-resolved vertical velocities over the $2-\mathrm{km}$ mesh but is completely neglected on the coarser scales. Conceivably, a parameterization to alleviate this problem could be devised, possibly by creating a fictitious "suspension velocity," somehow related to mean boundary layer TKE, which would allow for a more realistic treatment of drizzle drop production on larger scales. However, the uncertainty in the relationship between in-cloud drizzle drop residence time and the cloud dynamic structure needs to be explored before significant physical grounds exist to formulate a sensible parameterization.

Acknowledgments. Suggestions from Bjorn Stevens and an anonymous reviewer improved the focus of the manuscript. We appreciate helpful discussions with Graham Feingold, Brian Fiedler, Fanyou Kong, Robert Wood, and Lan Yi. Arulmani supplied the SSM/I LWP data and the AVHRR imagery. Robert Wood provided the JJA TMI climatology. J. Tim Kwiatkowski provided graphics support. This research was supported by ONR N00014-96-1-0687 and N00014-96-1-1112.

\section{REFERENCES}

Albrecht, B. A., 1989: Aerosol, cloud microphysics, and fractional cloudiness. Science, 245, 1227-1230.

— D. A. Randall, and S. Nicholls, 1988: Observations of marine stratocumulus clouds during FIRE. Bull. Amer. Meteor. Soc., 69, 618-626.

Austin, P., Y. Wang, R. Pincus, and V. Kujala, 1995: Precipitation in stratocumulus clouds: Observational and modeling results. $J$. Atmos. Sci., 52, 2329-2352.

Baker, M. B., 1993: Variability in concentrations of cloud condensation nuclei in the marine cloud-topped boundary layer. Tellus, 45B, 458-472.

Bretherton, C. S., and M. C. Wyant, 1997: Moisture transport, lower tropospheric stability, and decoupling of cloud-topped boundary layers. J. Atmos. Sci., 54, 148-167.

Chen, C., and W. R. Cotton, 1987: The physics of the marine stratocumulus-capped mixed layer. J. Atmos. Sci., 44, 2951-2977.

Feingold, G., B. Stevens, W. R. Cotton, and A. S. Frisch, 1996: The relationship between drop in-cloud residence time and drizzle production in numerically simulated stratocumulus clouds. $J$. Atmos. Sci., 53, 1108-1122.

Fiedler, B. H., 1984: The mesoscale stability of entrainment into cloud-topped mixed layers. J. Atmos. Sci., 41, 92-101.

Hodur, R. M., 1997: The Naval Research Laboratory's Coupled Ocean/Atmosphere Mesoscale Prediction System. Mon. Wea. Rev., 125, 1414-1430.

Jensen, J. B., S. Lee, P. B. Krummel, J. Katzfey, and D. Gagoasa, 2000: Precipitation in marine cumulus and stratocumulus. Part I: Thermodynamic and dynamic observations of closed cell circulations and cumulus bands. Atmos. Res., 54, 117-155.

Jiang, H., G. Feingold, and W. R. Cotton, 2002: Simulations of aerosol-cloud-dynamical feedbacks resulting from entrainment of aerosol into the marine boundary layer during the Atlantic Stratocumulus Transition Experiment. J. Geophys. Res., 107, 4813, doi:10.1029/2001JD001502.

Kessler, E., 1969: On the Distribution and Continuity of Water Substance in Atmospheric Circulation. Meteor. Monogr., No. 32, Amer. Meteor. Soc., 84 pp.

Khairoutdinov, M. F., and Y. L. Kogan, 1999: A large eddy simulation model with explicit microphysics: Validation against aircraft observations of a stratocumulus-topped boundary layer. J. Atmos. Sci., 56, 2115-2131.

— large-eddy simulation model of marine stratocumulus. Mon. Wea. Rev., 128, 229-243.

Kogan, Y. L., M. P. Khairoutdinov, D. K. Lilly, Z. N. Kogan, and Q. 
Liu, 1995: Modeling of stratocumulus cloud layers in a large eddy simulation model with explicit microphysics. J. Atmos. Sci. 52, 2923-2940.

Kong, F., 2002: An experimental simulation of a coastal fog-stratus case using COAMPS model. Atmos. Res., 64, 205-215.

Krueger, S. K., G. T. McLean, and Q. Fu, 1995: Numerical simulation of the stratus-to-cumulus transition in the subtropical marine boundary layer. Part I: Boundary-layer structure. J. Atmos. Sci., 52, 2839-2850.

Lewellen, D. C., and W. S. Lewellen, 2002: Entrainment and decoupling relations for cloudy boundary layers. J. Atmos. Sci., 59, 2966-2986.

Lilly, D. K., 1968: Models of cloud-topped mixed layers under a strong inversion. Quart. J. Roy. Meteor. Soc., 94, 292-309.

Martin, G. M., D. W. Johnson, and A. Spice, 1994: The measurement and parameterization of effective radius of droplets in warm stratocumulus clouds. J. Atmos. Sci., 51, 1823-1842.

McCaa, J. R., and C. S. Bretherton, 2003a: A new parameterization for shallow cumulus convection and its application to marine subtropical cloud-topped boundary layers. Part I: Description and 1-D results. Mon. Wea. Rev., submitted.

— convection and its application to marine subtropical cloudtopped boundary layers. Part II: Regional simulations of marine boundary layer clouds. Mon. Wea. Rev., submitted.

Mellor, G. L., and T. Yamada, 1982: Development of a turbulence closure model for geophysical fluid problems. Rev. Geophys. Space Phys., 20, 851-875.

Mishchenko, M. I., L. D. Travis, W. B. Rossow, B. Cairns, B. E. Carlson, and Q. Han, 1997: Retrieving CCN column density from single-channel measurements of reflected sunlight over the ocean: A sensitivity study. Geophys. Res. Lett., 24, 2655-2658.

Mocko, D. M., and W. R. Cotton, 1995: Evaluation of fractional cloudiness parameterizations for use in a mesoscale model. $J$. Atmos. Sci., 52, 2884-2901.

Moeng, C.-H., 1986: Large-eddy simulation of a stratus-topped boundary layer. Part I: Structure and budgets. J. Atmos. Sci., 43, 2886-2900.

—_, and Coauthors, 1996: Simulation of a stratocumulus-topped boundary layer: Intercomparison among different numerical codes. Bull. Amer. Meteor. Soc., 77, 261-278.

O’Dowd, C. D., M. H. Smith, A. D. Kaye, and J. Lowe, 1996: The relative importance of NSS-sulphate and sea-salt aerosol to the marine CCN population. Proc. 12th Int. Conf. on Clouds and Precipitation, Zurich, Switzerland, International Commission on Clouds and Precipitation, 334-337.

Paluch, I. R., and D. H. Lenschow, 1991: Stratiform cloud formation in the marine boundary layer. J. Atmos. Sci., 48, 2141-2158.

Rand, H. A., and C. S. Bretherton, 1993: Relevance of the mesoscale entrainment instability to the marine cloud-topped atmospheric boundary layer. J. Atmos. Sci., 50, 1152-1158.

Rothermel, J., and E. M. Agee, 1980: Aircraft investigation of mesoscale cellular convection during AMTEX 75. J. Atmos. Sci., 37, 1027-1040.

Shao, Q., and D. A. Randall, 1996: Closed mesoscale cellular convection driven by cloud-top radiative cooling. J. Atmos. Sci., 53, $2144-2165$.

Slingo, A., 1990: Sensitivity of the earth's radiation budget to changes in low clouds. Nature, 343, 49-51.

Stevens, B., 2000: Cloud transitions and decoupling in shear-free stratocumulus-topped boundary layers. Geophys. Res. Lett., 27, $2557-2560$.

— W W. R. Cotton, G. Feingold, and C.-H. Moeng, 1998: Largeeddy simulations of strongly precipitating, shallow, stratocumulus-topped boundary layers. J. Atmos. Sci., 55, 3616-3638.

_ C.-H. Moeng, and P. P. Sullivan, 1999: Large-eddy simulations of radiatively driven convection: Sensitivities to the representation of small scales. J. Atmos. Sci., 56, 3963-3984.

Turton, J. D., and S. Nicholls, 1987: A study of the diurnal variation of stratocumulus using a multiple mixed layer model. Quart. J. Roy. Meteor. Soc., 113, 969-1009.

Twomey, S., 1977: The influence of pollution on the short wave albedo of clouds. J. Atmos. Sci., 34, 1149-1152.

Wang, S., 1993: Modeling marine boundary-layer clouds with a twolayer model: A one-dimensional simulation. J. Atmos. Sci., 50, 4001-4021.

— , and Q. Wang, 1994: Roles of drizzle in a one-dimensional third-order turbulence closure model of the nocturnal stratustopped marine boundary layer. J. Atmos. Sci., 51, 1559-1576.

_ B. A. Albrecht, and P. Minnis, 1993: A regional simulation of marine boundary-layer clouds. J. Atmos. Sci., 50, 4022-4043.

Wentz, F. J., 1989: User's manual for SSM/I antenna temperature tapes. Remote Sensing Systems Tech. Rep. 032588, Remote Sensing Systems, Santa Rosa, CA, 36 pp.

Wood, R., 2000: The validation of drizzle parameterizations using aircraft data. Proc. 13th Int. Conf. on Clouds and Precipitation, Reno, NV, International Commission on Clouds and Precipitation, 530-533.

— C. S. Bretherton, and D. L. Hartmann, 2002: Diurnal cycle of liquid water path over the subtropical and tropical oceans. Geophys. Res. Lett., 29, 2092, doi:10.1029/2002GL015371.

Wyant, M. C., C. S. Bretherton, H. A. Rand, and D. E. Stevens, 1997: Numerical simulations and a conceptual model of the stratocumulus to trade cumulus transition. J. Atmos. Sci., 54, 168192.

Yuter, S. E., and R. A. Houze Jr., 1995: Three-dimensional kinematic and microphysical evolution of Florida cumulonimbus. Part II: Frequency distributions of vertical velocity, reflectivity, and differential reflectivity. Mon. Wea. Rev., 123, 1941-1963. 